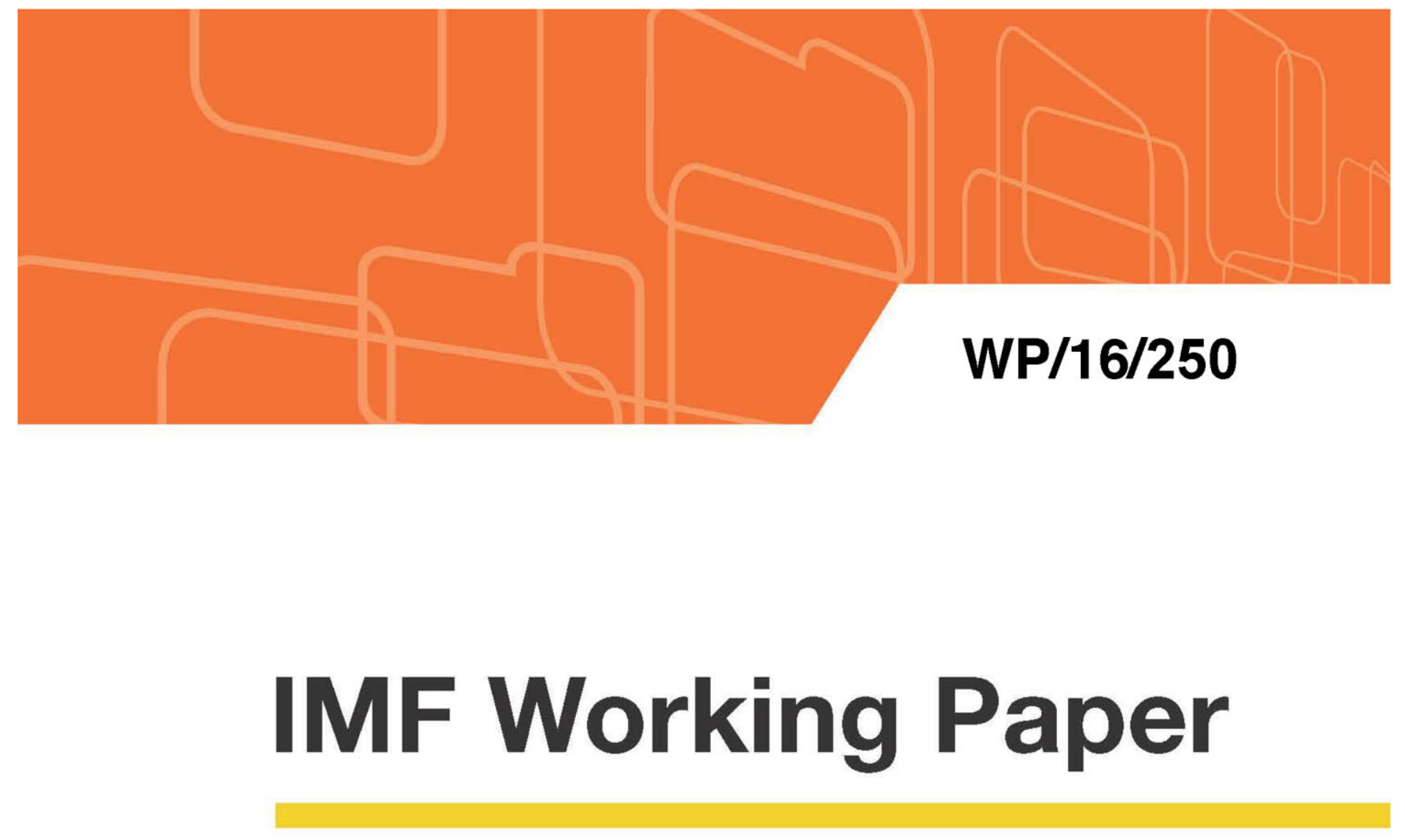

\title{
Potential Output Growth Estimates for Central America and the Dominican Republic
}

Roberto Garcia-Saltos, lulia Ruxandra Teodoru, and Fan Zhang

IMF Working Papers describe research in progress by the author(s) and are published to elicit comments and to encourage debate. The views expressed in IMF Working Papers are those of the author(s) and do not necessarily represent the views of the IMF, its Executive Board, or IMF management. 


\section{WP/16/250}

\section{IMF Working Paper}

\section{Potential Output Growth Estimates for Central America and the Dominican Republic}

Roberto Garcia-Saltos, Iulia Ruxandra Teodoru, and Fan Zhang

IMF Working Papers describe research in progress by the author(s) and are published to elicit comments and to encourage debate. The views expressed in IMF Working Papers are those of the author(s) and do not necessarily represent the views of the IMF, its Executive Board, or IMF management.

I N T E R N A T I O N A L M O N E TAR Y F U N D 


\title{
IMF Working Paper
}

Western Hemisphere Department

\section{Potential Output Growth Estimates for Central America and the Dominican Republic ${ }^{1}$ Prepared by Roberto Garcia-Saltos, Iulia Ruxandra Teodoru, and Fan Zhang Authorized for distribution by Lorenzo Figliuoli}

December 2016

\section{IMF Working Papers describe research in progress by the author(s) and are published to elicit comments and to encourage debate. The views expressed in IMF Working Papers are those of the author(s) and do not necessarily represent the views of the IMF, its Executive Board, or IMF management.}

\begin{abstract}
This paper presents estimates of potential output for all Central American economies. Our findings are that potential output growth has declined in recent years in most economies of Central America. Lower capital accumulation and TFP growth are accounting for most of this decline. Apart from Costa Rica, there are no indications of significant economic slack in 2015 in Central America. Looking forward, potential growth in most Central American economies is expected to continue at an average of 4 percent in the medium-term due to structural constraints to capital and employment growth, and low TFP growth. Increasing potential growth, thus, should be a policy priority and structural reforms must be directed at improving business conditions, product and labor markets, and enhancing the capacity for innovation.
\end{abstract}

JEL Classification Numbers: C51, E31, E52

Keywords: potential output, productivity, macroeconomic modeling, production function, Central America

Author's E-Mail Address: rgarciasaltos@,imf.org; iteodoru@,imf.org; fzhang@,imf.org.

\footnotetext{
${ }^{1}$ The paper has benefited from the insightful comments of Valerie Cerra, Manuel Coronel, Carlos Janada, Hadzi-Vaskov Metodij, Rosalind Colleen Mowatt, Gerardo Peraza, and the Central Bank of Guatemala.
} 
Contents Page

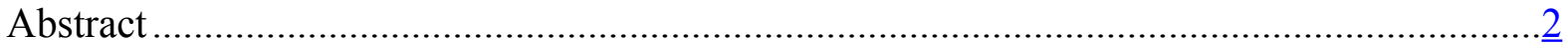

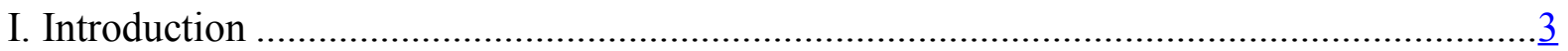

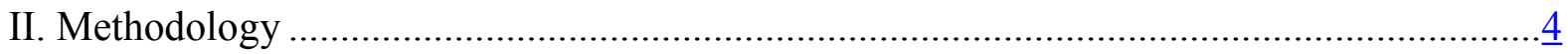

III. How Did Potential Growth Evolve Before The Crisis? ................................................. 9

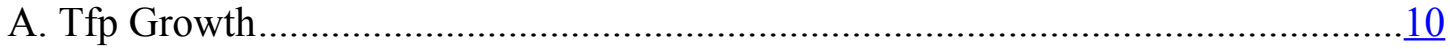

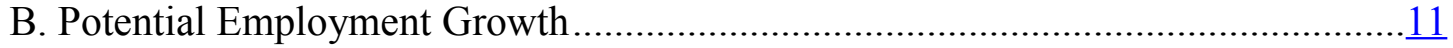

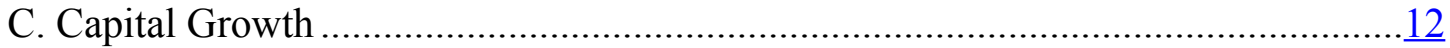

IV. Potential Growth In The Aftermath Of The Global Financial Crisis ..............................14

V. What Is The Likely Trajectory Of Potential Growth In The Medium Term?....................15

VI. Conclusion And Policy Recommendations ........................................................... 17

Figures

1. Output Compared to Precrisis Expectations in Central America........................................19

2. Contributions of Components of Potential Output Growth in Central America .................20

3. Contributions of Components of Potential Output Growth in Central America ................ 21

4. Components of Capital Growth in Central America...................................................

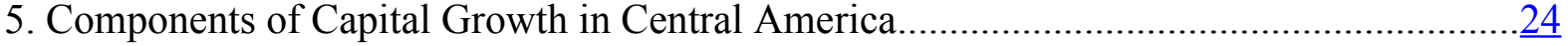

6. Components of Potential Employment Growth in Central America .................................25

7. Components of Potential Employment Growth in Central America ................................26

8. Investment-to-Capital Ratio in Central America ......................................................... $\frac{27}{28}$

9. Components of Potential Employment Growth in Central America ...............................28

10. Contributions of Components of Potential Output Growth in Central ............................29 


\section{INTRODUCTION}

Potential output growth across Central America has declined in recent years. For most of the countries, this decline started after the global financial crisis (GFC). In Panama, on the other hand, potential growth has not been affected by the crisis and has continued at rates similar to pre-GFC. While in the Dominican Republic, Guatemala, and El Salvador potential growth has recovered somewhat in the past two years, it is still well below pre-crisis rates (only in Nicaragua, it fully recovered to pre-crisis rates). El Salvador has the lowest potential growth in Central America (1.8 percent), and all economies, except Panama, exhibit lower potential growth compared to other emerging markets (5.4

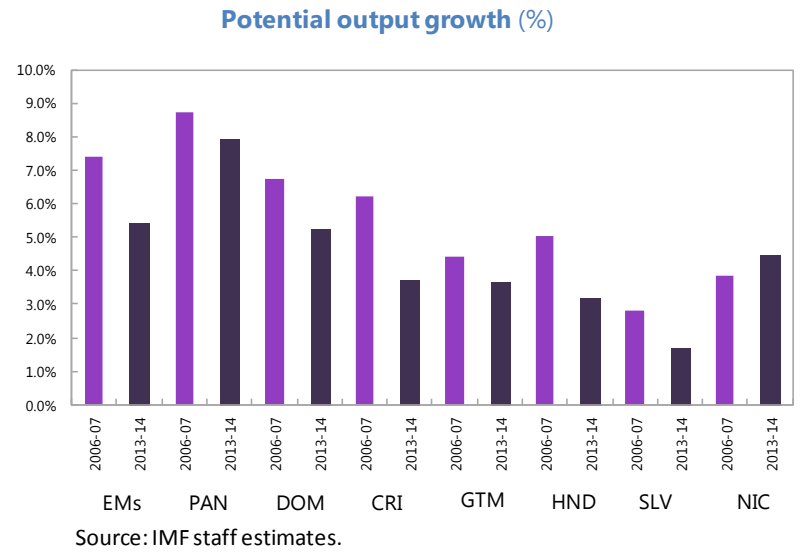
percent). Potential growth in Central America is expected to continue at a similar rate due to weak investment, somewhat stagnant employment creation, and low growth in total factor productivity (TFP).

In these economies, average real output growth remains much lower than in 2008, just before the onset of the GFC. Only for Panama, its growth rate has been higher than before the GFC, supported by the Panama Canal expansion. Moreover, medium-term (five-year-ahead) growth projections have been steadily revised downward for most Central American economies but for Panama and Nicaragua (Figure 1). The repeated downward revisions to medium-term growth forecasts, where outturns were much worse than initial forecasts, highlight the uncertainties surrounding

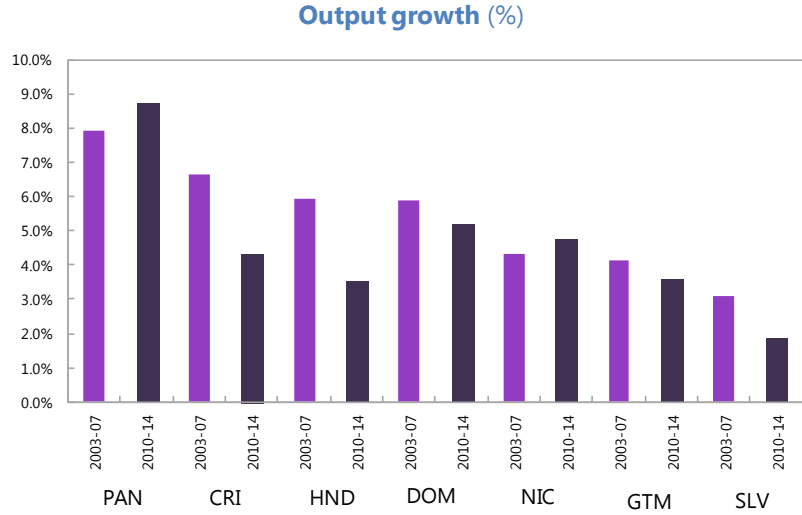

Source: IMF staff estimates. prospects for the growth rate of potential output.

A better understanding of how the components of potential growth-labor, capital accumulation, and TFP — contribute to the overall slowdown can help guide the discussion on structural reforms needed to raise it. This paper constructs estimates of potential output for all Central American economies by using a multivariate filter approach. In this context, it seeks to answer the following questions: How did the potential output and its components evolve from the early 2000s until the GFC? What happened to the level and 
growth rate of potential output and its components during the GFC? What could be the likely trajectory of potential output in the medium-term? What are the policy implications?

Before the crisis, potential growth increased in all Central American economies. The average increase was about 2 percentage points from about $3^{1 / 3}$ percent to $5^{1 / 3}$ percent from 2001 to 2007, with Panama, the Dominican Republic, and Costa Rica driving much of this increase. This increase in potential growth is attributable mostly to increases in labor and less of a drag from TFP in Guatemala, and increases in capital accumulation and TFP in Costa Rica, the Dominican Republic, Honduras, and Panama.

In the aftermath of the crisis, potential growth declined in most Central American economies. Potential growth declined by about 2 percentage points in Costa Rica, the Dominican Republic, and Honduras from 2006-07 to 2013-14, slightly more than 1 percentage point in El Salvador, and less than 1 percentage point in Guatemala and Panama, while it increased slightly in Nicaragua. Lower capital accumulation and TFP are accounting for most of the decline in potential growth. In comparison, potential output in emerging markets declined by about 2 percentage points over the same period, with lower TFP accounting for much of the decline (WEO, April 2015). ${ }^{2}$

Looking forward, potential growth in most Central American economies is expected to continue at an average of 4 percent during the medium term, lower than the pre-crisis average. This weakness appears as a result of structural constraints to capital and employment growth, and low TFP growth, perhaps originated in insufficient efforts to foster technological progress and subpar development of a more stable institutional, regulatory, and legal environment. Increasing potential growth, thus, is a policy priority in most Central American economies. Lower potential growth will make it difficult to rebuild fiscal buffers or reduce high debt ratios in some economies. Structural reforms must be directed at improving business conditions, product and labor markets, and enhancing the capacity for innovation.

\section{Methodology}

Potential output is generally thought of as the level of output that can be achieved without giving rise to inflation (Okun, 1962). In the short term, actual output will deviate temporarily from potential as shocks hit the economy. These deviations reflect the slow adjustment in wages and prices to shocks, which means that the reversion of output to its potential level is gradual. Okun's definition is particularly prevalent among monetary policy makers, as it allows them to communicate their policy stance in the context of the short-run tradeoff between output and inflation. The economic definition of potential differs from the widely used concept of trend output, because it relies on an explicit framework based on economic theory.

Trend output, in contrast, is derived from simple statistical data filtering using various forms of moving averages or deterministic trends. The appeal of this approach is that it is simple, transparent, and can be applied to any country where GDP data exist. As a result, this

\footnotetext{
${ }^{2}$ World Economic Outlook, Chapter 3: Where Are We Headed? Perspectives on Potential Output (April 2015).
} 
technique is widely applied in emerging-market economies, where data scarcity renders many other approaches infeasible. Unfortunately, the approach's relative simplicity brings with it several notable limitations. Chief among these is that the estimates do not incorporate any economic structure (e.g. the assumption is that an economy is, on average, in a state of full capacity, without incorporating information from variables such as inflation or unemployment), and thus are not consistent with an economic concept of potential. In addition, univariate filters suffer from a particularly acute 'end-of-sample' problem, with estimates towards the end of a given sample period being subject to significant revisions as more data ultimately become available and the sample is extended.

Another common technique to estimating potential output is the production-function approach, in which the inputs of production are considered separately. In its simplest form, this entails specifying a two-factor production function (generally Cobb-Douglas), obtaining data on employment and the capital stock, and then deducing total-factor productivity (TFP) as the residual from the production-function equation. By smoothing the resulting TFP series, and specifying a process for 'potential' employment, one arrives at an estimate for potential output by combining these trends with the estimate of the capital stock. ${ }^{3}$ This approach has the benefit of allowing for a more detailed examination of the drivers of potential. However, there are also limitations; in particular, reliable capital-stock data can be hard to obtain, and the estimates of potential arising from this approach are only as good as the filters used to de-trend the TFP and employment components. ${ }^{4}$

Next, a good deal of work has focused on the use of multivariate filters to estimate potential (see Laxton and Tetlow (1992), Kuttner (1994), and more recently Benes and others (2010), and Blagrave and others (2015), among others). This approach adds economic structure to estimates by conditioning them on some basic theoretical relationships (such as a Phillip's curve relating the inflation process to the output gap). One strength of this approach is that estimates of the output gap and potential are consistent with the Okun concept of potential. In addition, in its simplest form this technique is relatively easy to implement requiring only a few variables, and it can be augmented where data availability permits.

The multivariate filter approach specified in this paper follows this thread of literature by adding economic structure to the estimates of potential. The model incorporates information on the relationship between cyclical unemployment and inflation (Phillip's curve) on one hand, and between cyclical unemployment and the output gap (Okun's law) on the other. It is relatively simple, requiring data on just three observable variables: real GDP growth, CPI inflation, and the unemployment rate. We present the equations which relate these three observable variables to the latent variables in the model in the next section. Parameter values and the variances of shock terms for these equations are estimated using Bayesian estimation techniques. ${ }^{5}$ To the best of our knowledge, no similar approach for

\footnotetext{
${ }^{3}$ For an example of how the production-function approach can be implemented, see D'Auria and others (2010).

${ }^{4}$ As an example, if the employment and TFP series are de-trended using an HP filter, then the resulting estimates of potential output will have almost identical properties to those arising from a direct HP filtration of GDP data.

${ }^{5}$ More specifically, we use regularized maximum likelihood techniques (see Ljung, 1999). Also, see Hamilton (1994) for a general discussion of the Kalman filter, which is used to obtain estimates of the unobservable variables as part of the estimation process. Parameter estimates are provided in an appendix.
} 
estimating potential output has been applied to Central American countries before. A further contribution of the paper is that, in the absence of market expectations for growth and inflation, it uses WEO forecasts to account for inflation and growth expectations, which could be potentially important for other countries where data on inflation and growth expectations do not exist. Historical results presented in the paper are consistent with previous findings estimated through different methods, including Johnson, 2013, and Western Hemisphere REO, 2013. The main difference is that the multivariate filter captures much better shocks that have a lasting effect on the economy, as it does not smooth the output as the HP filter does, given that it incorporates additional information from inflation and unemployment to pin down potential growth.

The stochastic process for output (real GDP) is comprised of three equations, and subject to three types of shocks:

$$
\begin{aligned}
& \bar{Y}_{t}=\bar{Y}_{t-1}+G_{t}+\varepsilon_{t}^{\bar{Y}} \\
& G_{t}=\theta G^{S S}+(1-\theta) G_{t-1}+\varepsilon_{t}^{G} \\
& y_{t}=\phi y_{t-1}+\varepsilon_{t}^{y}
\end{aligned}
$$

In the model, the output gap is defined as the deviation of real GDP, in log terms $(Y)$, from its potential level $(\bar{Y})$ :

$$
y=Y-\bar{Y}
$$

The level of potential output $\left(\bar{Y}_{t}\right)$ evolves according to potential growth $\left(G_{t}\right)$ and a levelshock term $\left(\varepsilon_{t}^{\bar{Y}}\right)$. Potential growth is also subject to shocks $\left(\varepsilon_{t}^{G}\right)$, with their impact fading gradually according to the parameter $\theta$ (with lower values entailing a slower adjustment back to the steady-state growth rate following a shock). Finally, the output-gap is also subject to shocks $\left(\varepsilon_{t}^{y}\right)$, which are effectively demand shocks. The role of each shock term is expressed graphically in the figure below:

\section{Shocks to the level and growth rate of potential output, and the output gap}




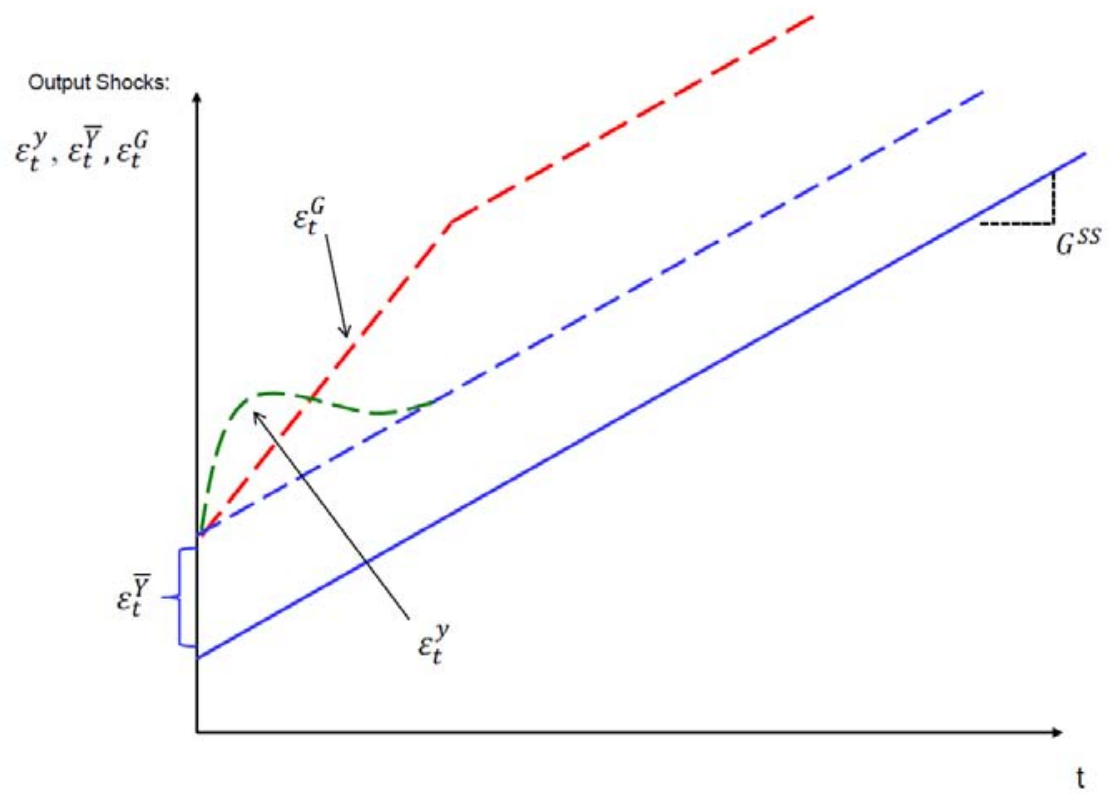

All else equal, output would be expected to follow its steady-state path, which is shown above by the solid blue line (which has a slope of $G^{S S}$ ). However, shocks to: the level of potential $\left(\varepsilon_{t}^{\bar{Y}}\right)$; the growth rate of potential $\left(\varepsilon_{t}^{G}\right)$; or the output gap $\left(\varepsilon_{t}^{y}\right)$, can cause output to deviate from this initial steady-state path over time. As shown by the dashed blue line, a shock to the level of potential output in any given period will cause output to be permanently higher (or lower) than its initial steady-state path. Similarly, shocks to the growth rate of potential, illustrated by the dashed red line, can cause the growth rate of output to be higher temporarily, before ultimately slowing back to the steady-state growth rate (note that this would still entail a higher level of output). And, finally, shocks to the output gap would cause only a temporary deviation of output from potential, as shown by the dashed green line.

To help identify the three aforementioned output shock terms, a Phillips curve equation for inflation and equations describing the evolution of unemployment ${ }^{6}$ (an Okun's law) are added. This links the evolution of the output gap (an unobservable variable) to observable data on inflation ${ }^{7}$ and unemployment:

$$
\begin{aligned}
& \pi_{t}=\lambda \pi_{t+1}+(1-\lambda) \pi_{t-1}+\beta y_{t}+\varepsilon_{t}^{\pi} \\
& \bar{U}_{t}=\left(\tau_{4} \bar{U}^{s s}+\left(1-\tau_{4}\right) \bar{U}_{t-1}\right)+g \bar{U}_{t}+\varepsilon_{t}^{\bar{U}}
\end{aligned}
$$

${ }^{6}$ Data on unemployment is of uncertain quality, especially given high informality, and thus, estimates of the NAIRU should be interpreted with caution.

${ }^{7}$ Some recent work suggests that the slope of the Phillips curve relationship $(\beta)$ has flattened over the past several decades (IMF, 2013), whereas other studies suggest that it may have steepened in some countries in recent years (Riggi and Venditti, 2014). Although the methodology in this paper does not allow for time variation in parameter estimates, modest changes in the estimated value of the parameter $\beta$, on its own, do not materially change the estimates of potential output. 


$$
\begin{aligned}
& g \bar{U}_{t}=\left(1-\tau_{3}\right) g \bar{U}_{t-1}+\varepsilon_{t}^{g \bar{U}} \\
& u_{t}=\tau_{2} u_{t-1}+\tau_{1} y_{t}+\varepsilon_{t}^{u} \\
& u_{t}=\bar{U}_{t}-U_{t}
\end{aligned}
$$

Here, $\bar{U}_{t}$ is the equilibrium value of the unemployment rate (the NAIRU), which is time varying, and subject to shocks $\left(\varepsilon_{t}^{\bar{U}}\right)$ and also variation in the trend $\left(g \bar{U}_{t}\right)$, which is itself also subject to shocks $\left(\varepsilon_{t}^{g \bar{U}}\right)$ - this specification allows for persistent deviations of the NAIRU from its steady-state value. Most importantly, we specify an Okun's law relationship wherein the gap between actual unemployment $\left(U_{t}\right)$ and its equilibrium process (given by $u_{t}$ ) is a function of the amount of slack in the economy $\left(y_{t}\right)$. Equations 1-9 comprise the core of the model for potential output.

\section{In addition, data on growth and inflation expectations are added, in part to help identify shocks, but mostly to improve the accuracy of estimates at the end of the sample period:}

$$
\begin{aligned}
& \pi_{t+j}^{C}=\pi_{t+j}+\varepsilon_{t+j}^{\pi^{C}}, \mathrm{j}=0,1 \\
& \text { GROWTH } H_{t+j}^{C}=G R O W T H_{t+j}+\varepsilon_{t+j}^{G R O W T H^{C}}, \mathrm{j}=0, \ldots, 5
\end{aligned}
$$

For real GDP growth (GROWTH) the model is augmented with forecasts from the WEO for the five years following the end of the sample period. For inflation, expectations data are added for one year following the end of the sample period. These equations relate the modelconsistent forward expectation for growth and inflation $\left(\pi_{t+j}\right.$ and $\left.G R O W T H_{t+j}\right)$ to observable data on how WEO forecasters expect these variables to evolve over various horizons (one to five years ahead) at any given time $\left(G R O W T H_{t+j}^{C}\right)$. The 'strength' of the relationship between the data on the WEO forecasts and the model's forward expectation is determined by the standard deviation of the error terms $\left(\varepsilon_{t+j}^{\pi^{C}}\right.$ and $\left.\varepsilon_{t+j}^{G R O W T H^{C}}\right)$. In practice, the estimated variance of these terms allows WEO data to influence, but not completely override, the model's expectations, particularly at the end of the sample period. In a way, the incorporation of WEO forecasts can be thought as an heuristic approach to blend forecasts from different sources and methods. 
The methodology requires taking a stance on prior beliefs regarding a number of variables. A key assumption fed into the model's estimation is that supply shocks are the primary source of real GDP fluctuations in Central America. The prior belief that supply is more volatile than demand leads the model to assign much of the observed volatility of real GDP to potential GDP fluctuations. In addition to the prior distributions of parameters, values for the steady-state (long-run) unemployment rate $^{8}$ and potential GDP growth rates are provided.

\section{After obtaining estimates of potential output and} NAIRU from the multivariate Kalman filter, the analysis investigates the drivers of potential growth using a growth-accounting framework based on a standard CobbDouglas production function. This framework describes how the economy's potential output is determined by factor inputs (capital and labor) and productivity (TFP). Potential TFP is calculated as a residual in the Cobb-Douglas function:

$$
A_{t}=Y_{t} / K_{t}^{\alpha} L_{t}^{1-\alpha}
$$

where $Y_{t}$ is potential output, $K_{t}$ and $L_{t}$ are capital and labor inputs, while $A_{t}$ is the contribution of technology or TFP. Output elasticities ( $\alpha$ is the capital share in the production function and is set at 0.35$)^{9}$ sum up to one. Data on the working age population and the labor force participation rate is obtained from the UN Economic Commission for Latin American and the Caribbean (CEPAL). The capital stock series is constructed using a perpetual inventory method where the level of initial capital stock for a given year, 1990 in our case, is calculated assuming a constant level of depreciation rate of 5 percent per annum and a constant investment share of GDP. ${ }^{10}$

\section{How Did Potential Growth Evolve Before the Crisis?}

In Central American economies, potential growth increased from 3.2 percent to 5.4 percent during 2001-07. While this exceptional growth was partly driven by the strong

\footnotetext{
${ }^{8}$ Differences in the steady state unemployment rates may respond to differences in labor institutions.

${ }^{9}$ Estimates for the capital share are in line with other estimates found in the literature such as the Western Hemisphere REO, Chapter 3: Is the Growth Momentum in Latin America Sustainable, May 2013, and Loayza, N., P. Fajnzylber, C. Calderón, "Economic Growth in Latin America and the Caribbean: Stylized Facts, Explanations, and Forecasts," World Bank Study, World Bank and Central Bank of Chile Working Paper 265, June 2004.

${ }^{10}$ From the dynamic equation for capital accumulation, $K_{t}=(1-\delta) K_{t-1}+I_{t}$, we assume a constant depreciation rate and constant investment share over a 20 year period to obtain the initial capital stock for 1990 as $K_{1990}=\frac{I_{o}\left[\left(1-\delta^{20}\right)-1\right]}{-\delta}$. The results obtained for calculating capital stock this way albeit imperfect are broadly in line with other estimates found in the literature such as the Western Hemisphere REO, Chapter 3: Is the Growth Momentum in Latin America Sustainable, May 2013.
} 
performance of Panama, potential growth also increased in all other economies over this period, with the smallest increase occurring in El Salvador. The acceleration in TFP explains the bulk of the increase in potential growth in Costa Rica, the Dominican Republic, Nicaragua, and Panama. In Honduras, the increase in potential growth responded to faster capital accumulation and a small improvement in TFP, and in El Salvador and Guatemala it was employment creation and less of a drag from TFP (Figure 2).

\section{A. TFP growth}

TFP growth depends on technological progress as well as the institutional, regulatory, and legal environment in which businesses operate. TFP captures the efficiency with which labor and capital are combined to generate output, which, in turn, depends on businesses' ability to innovate, as well as an environment that fosters competition, removes unnecessary administrative burden, provides modern and efficient infrastructure, and allows easy access to finance.

Before the crisis, most countries experienced a significant rebound in TFP growth. TFP growth in 2006-07 increased in the years before the crisis to almost 2 percent in Costa Rica, over 3 percent in the Dominican Republic, and close to 5 percent in Panama (from close to 1 percent in 2001-03) (Figure 2). Honduras and Nicaragua saw some improvements in productivity growth in this period as well (to 1 percent). Possible explanations for this increase, leaving aside measurement errors, could include: shifts of resources to higherproductivity sectors such as circuitry and mechanical parts in Costa Rica, reparations and maintenance services, and high-tech equipment in Panama, and electrical equipment and medical instruments in the Dominican Republic. Greater diversification of exports and economic complexity (the amount of productive knowledge that is embodied in the export content) likely contributed to the high TFP growth and long-term growth. For example, Costa Rica diversified exports to sectors characterized by technology spillovers and upgrading of quality of products (from agricultural products and garments in the late 1980s to circuitry and mechanical parts in 2008), and the Dominican Republic - from garments, tobacco, and mining to electrical machinery, medical instruments, and metal products. Panama and the Dominican Republic rank highest in Latin America and the Caribbean in terms of economic complexity and their complexity has been increasing (Hausmann (2013), and Western Hemisphere REO (April 2015)). ${ }^{11}$ The Western Hemisphere REO (April 2015) found that more complex and diversified economies tend to have higher GDP per capita growth.

\section{TFP growth has been absent in EI Salvador and Guatemala, with some minimal improvements in Guatemala in the years before the crisis. Productivity shortfalls in El Salvador and Guatemala, and to a lesser extent in Honduras and Nicaragua may reflect among other factors, lags in investment in R\&D and adoption and development of new technologies. Lower human capital growth (El Salvador, and Honduras saw a significant decline in human capital growth from 2001 to 2007) and migration of high-skilled workers seem to have hampered TFP growth. In addition, productivity gains are also hindered by a}

\footnotetext{
${ }^{11}$ R. Hausmann, The Atlas of Economic Complexity: Mapping Paths to Prosperity (2013); Western Hemisphere Regional Economic Outlook, Chapter 5: Long-Run Growth in Latin America and the Caribbean: The Role of Economic Diversification and Complexity (April 2015).
} 
lack of competition and high market concentration. Weak business environment, including political and economic uncertainty, poor security, high red tape and corruption, lack of legal/judicial stability, high costs of infrastructure and poor quality are additional factors hindering TFP.

\section{B. Potential employment growth}

Central American economies seem to have benefited from demographic dividends starting in the mid-1960s, and some even later. At an early stage of the demographic transition from high fertility/mortality rates to low fertility/mortality rates, the share of the working age population increases. At a later stage, a second dividend is possible if a population concentrated at older working ages and facing an extended period of retirement accumulates assets and invests them in the economy. The share of the working-age population increased across the board in all economies (Figure on Demographic Indicators). Costa Rica, followed by Panama and the Dominican Republic, had benefited from demographic dividends starting in the mid-1960s, and had completed between 50-60 percent of their transition by 2007, while Guatemala, Honduras, Nicaragua, and El Salvador had completed only 10-40 percent of their transition by 2007 and thus benefited from a demographic dividend in the early 2000 s to a larger extent. At the same time, the dependency ratio in Costa Rica, Panama, and the Dominican Republic had already reached relatively low levels (below two-thirds) by the mid-2000s. In the rest of the economies, the dependency ratio was steadily declining, but was still above two-thirds, and in Guatemala it is still high and not declining much, highlighting the need to reduce it in order to reap the benefits in their demographic transition. Costa Rica, Panama, and the Dominican Republic experienced the highest GDP per capita in Central America, and reached higher middle-income status.

The increase in potential growth in the 2000s in some countries was due to increases in potential employment growth. In El Salvador, potential employment growth increased from 1.5 percent to 1.9 percent and in Guatemala from 3.3 percent to 3.5 percent during the 2001 07 period, mainly attributable to higher working-age population growth (Figure 6). Fertility rates were falling in El Salvador for several decades (dropped 30 percent by the 80 s from the $60 \mathrm{~s}$ ), but mortality rates were dropping too and life expectancy increasing, which could explain the steady increase in the working-age population. In Guatemala, fertility rates and population growth are one of the highest in Central America and life expectancy has been steadily increasing, which can explain in part the high working-age population growth. Potential employment growth in the Dominican Republic, Honduras, and Nicaragua continued at the same rates over the 2001-07 period. In the Dominican Republic, fertility rates almost halved by the 1980s from the 60s, while in Honduras and Nicaragua, such significant reductions took place only more recently. The transition from high to low fertility rates was accompanied by lower mortality rates and higher life expectancy.

\section{Potential employment growth fell in Costa Rica and Panama during the 2001-07}

period. It fell from 3.5 percent to 3.1 percent in Costa Rica, and from 2.8 percent to 2.6 percent in Panama, mainly attributable to reduced growth rates of the working-age population. In these two countries, the share of working-age population in total population was increasing (i.e. they were still benefiting from a demographic dividend), but population 
growth must have slowed more than the slowdown in growth rates of the working-age population (i.e. mortality rates were increasing).

\section{Capital growth}

The evolution of capital deepening has been diverse across countries. Capital growth increased the most in Panama, from 3 percent to 6.8 percent, and in Honduras, from over 4.7 percent to 6.8 percent, during the 2001-07 period, and to an important extent in Costa Rica, the Dominican Republic and Guatemala from the mid-2000s, while it declined in Nicaragua and El Salvador (almost 1 percentage point in El Salvador). This acceleration in capital accumulation was driven by the strong increase in the investment-to-capital ratio over the period-from 7.5 percent to 11.5 percent in Panama, and from 9.2 percent to 11.5 percent in Honduras. The declines in Nicaragua and El Salvador have been driven by a decline in the investment-to-capital ratios. Capital goods imports were booming in most of these economies in the mid-2000s and as a consequence there was an overhauling of physical capital which supported an increase in potential growth in most economies (this was not the case in Nicaragua and El Salvador) (Figures $4 \mathrm{a}$ and $4 \mathrm{~b}$ ). 
Demographic Indicators
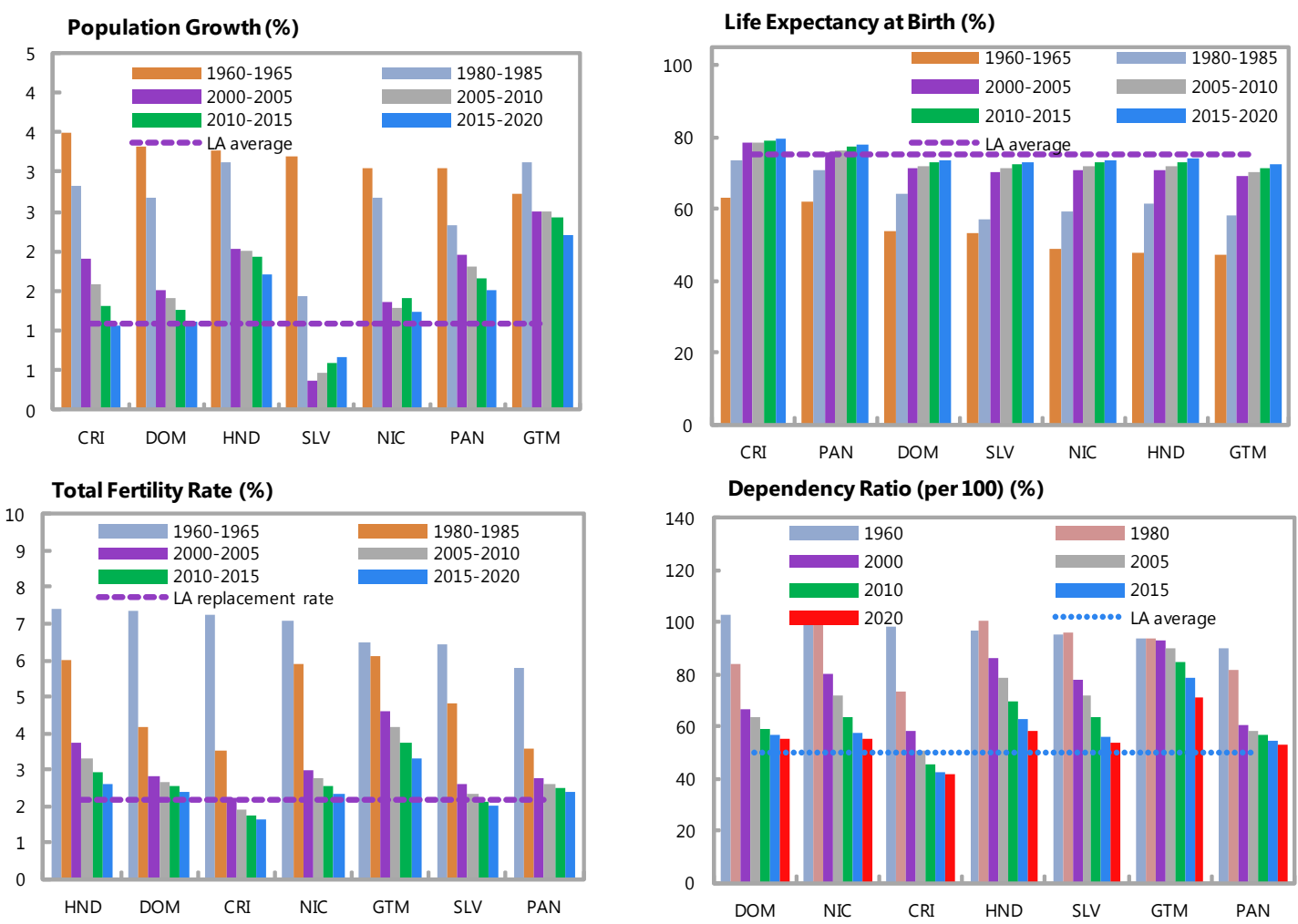

Share of Working Age Population (WAP) (\%)
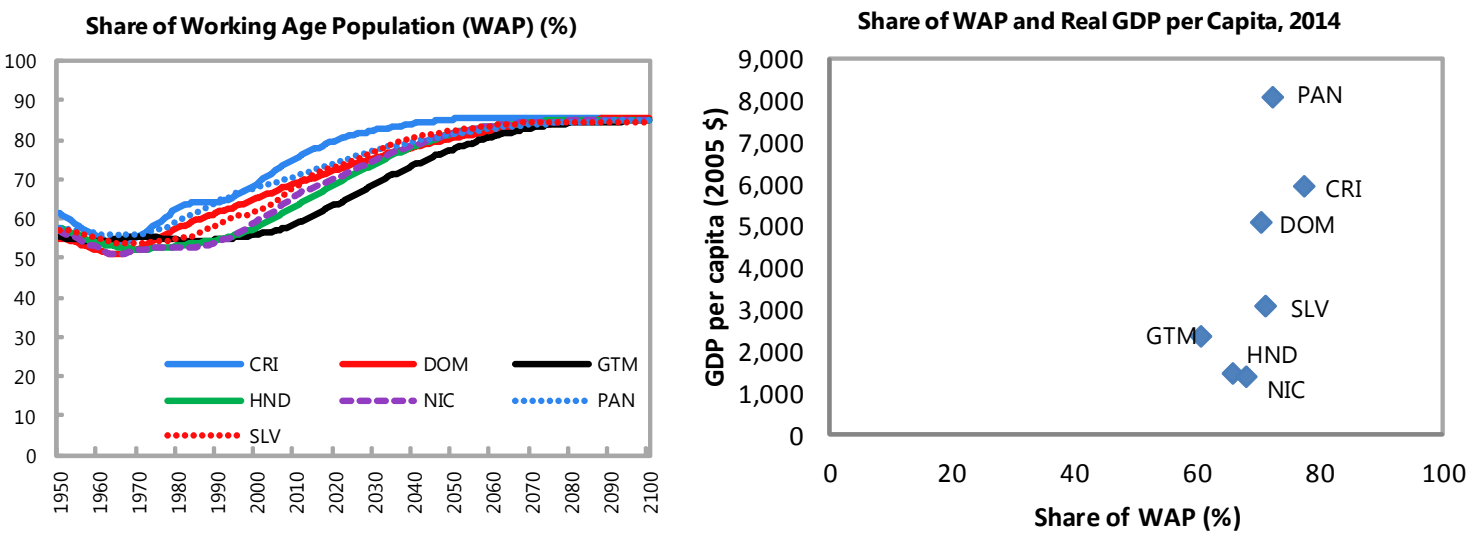

Source: UN Economic Commission for Latin America and the Caribbean (ECLAC) and WDI. 


\section{Potential Growth in the Aftermath of the Global Financial Crisis}

Potential growth declines after the GFC were significant in most Central American economies and were due to declines in capital and TFP growth, and to a lesser extent potential employment growth. Potential growth declined by about 2 percentage points in Costa Rica (from 6.2 to 3.9 percent), the Dominican Republic (from 6.8 to 5.2 percent), and Honduras (from 5 to 3.2 percent) from 2006-07 to 2013-14, slightly more than 1 percentage point in El Salvador, and less than 1 percentage point in Guatemala and Panama, while it increased slightly in Nicaragua (Figure 3). Potential growth in Central American economies decreased by less after the GFC compared to the average reduction in emerging market economies likely because of the economic links of these countries with the U.S. economy, which has been resilient in the face of financial market volatility, a strengthening dollar, and subdued global demand.

The decline in capital growth accounted for a large part of the decline in potential growth. The decline in capital growth was over 2 percentage points in the Dominican Republic, Guatemala, and El Salvador, and over 3.5 percentage points in Honduras). In Panama, the expansion of the canal and other important investment projects (e.g. metro line, new highways, urban development projects in the capital) brought about an expansion in capital growth (of 4 percentage points), and Nicaragua also experienced an increase in capital growth due to new energy projects, while capital growth in Costa Rica appears not to have been affected by the crisis (Figures 5 and 8).

The collapse in aggregate demand after the GFC can explain much of the decline in investment, and financial factors are an important transmission channel (as discussed in Chapter 3 of the April 2015 WEO). For example, as the supply of credit becomes limited, firms may face less advantageous financing terms and tighter lending standards over an extended period (Claessans and Kose, 2013). Moreover, financial crises weaken firms' incentives to invest because risks and uncertainty about expected returns tend to increase (Pindyck, 1991; Pindyck and Solimano, 1993). Financial crises can have a long-lasting effect

on potential growth if investment-to-capital ratios remain depressed for an extended period of time. As output and investment recover from crises, capital will return to its equilibrium growth path, but more gradually since it is a slow-moving variable. Although we do not have empirical evidence of this situation in Central America, we conjecture that some of these factors were also present in the region (Figure 5).

The decline in TFP growth in many Central American economies accounted for another part of the decline in potential growth. TFP growth declined by up to 1.9 percentage points from 2006-07 to 2013-14. Lower TFP may reflect reduced investment in innovation through research and development from the crisis, as well as continued weaknesses in the institutional, regulatory, and legal environment (Appendix II Figures 1-3). Lower TFP may also reflect lower human capital growth. In the Dominican Republic, Nicaragua, and Guatemala, however, TFP growth has recovered to pre-crisis rates, and its contribution to potential growth remained over 2.5 percent in the Dominican Republic and Panama. These two latter countries have the highest TFP growth in the region.

The decline in potential growth was further due to substantial declines in potential employment growth. In Costa Rica, potential employment growth fell by 0.8 percentage 
points from 2006-07 to 2013-14, due to a significant decline in working-age population growth, and by 0.3 percentage points in the Dominican Republic and Panama. Potential employment growth remained broadly stable in Honduras and Nicaragua, while it continued increasing after the crisis in El Salvador and Guatemala (by about 0.2 percentage points) (Figure 7). Immigration and remittances flows appear to have slowed significantly from 2008 to 2013-14, given lower labor demand in the U.S. after the GFC, which could explain part of the stable or increasing employment growth in the latter four countries.

U.S. Immigrant Population by Country of Birth, 2000-Present

\begin{tabular}{|c|c|c|c|c|c|c|c|c|c|c|}
\hline & 2000 & 2007 & 2008 & 2009 & 2010 & 2011 & 2012 & 2013 & $2000-07$ & 2008-13 \\
\hline Americas & 16,916 & 21,248 & 20,977 & 21,278 & 22,031 & 22,040 & 22,120 & 22,320 & 3.3 & 0.8 \\
\hline Latin America & 16,087 & 20,410 & 20,150 & 20,456 & 21,224 & 21,245 & 21,311 & 21,473 & 3.5 & 0.9 \\
\hline Caribbean & 2,953 & 3,387 & 3,408 & 3,466 & 3,731 & 3,777 & 3,873 & 3,954 & 2.0 & 2.6 \\
\hline Central America & 11,204 & 14,450 & 14,175 & 14,394 & 14,764 & 14,758 & 14,711 & 14,751 & 3.7 & 0.4 \\
\hline Costa Rica & 72 & 86 & 81 & 86 & 82 & 78 & 77 & 79 & 2.5 & -1.3 \\
\hline El Salvador & 817 & 1,104 & 1,095 & 1,150 & 1,214 & 1,265 & 1,272 & 1,252 & 4.4 & 2.2 \\
\hline Guatemala & 481 & 701 & 739 & 799 & 831 & 851 & 859 & 902 & 5.5 & 4.3 \\
\hline Honduras & 283 & 431 & 460 & 468 & 523 & 491 & 522 & 534 & 6.2 & 3.8 \\
\hline Nicaragua & 220 & 231 & 238 & 253 & 248 & 242 & 258 & 241 & 0.7 & 0.8 \\
\hline Panama & 105 & 102 & 96 & 104 & 99 & 104 & 103 & 101 & -0.4 & -0.1 \\
\hline Other Central America & 48 & 58 & 53 & 7 & 9 & 10 & 10 & 8 & 2.7 & -13.1 \\
\hline South America & 1,930 & 2,572 & 2,567 & 2,596 & 2,730 & 2,711 & 2,727 & 2,768 & 4.2 & 1.3 \\
\hline Northern America & 829 & 839 & 827 & 822 & 807 & 795 & 808 & 847 & 0.2 & 0.2 \\
\hline
\end{tabular}

Source: Migration Policy Institute tabulation of data from the U.S. Census Bureau's 2006 to 2013 American Community Survey and 2000 Decennial Census.

Migrant Remittance Inflows, 2000-Present (US\$ million)

\begin{tabular}{|c|c|c|c|c|c|c|c|c|c|c|c|}
\hline & 2000 & 2007 & 2008 & 2009 & 2010 & 2011 & 2012 & 2013 & 2014 & $2000-2007$ & 2008-2014 \\
\hline Costa Rica & 136 & 618 & 605 & 513 & 531 & 520 & 562 & 596 & 612 & 24.2 & 0.1 \\
\hline Dominican Republic & 1,840 & 3,397 & 3,606 & 3,415 & 3,887 & 4,241 & 4,262 & 4,486 & 4,650 & 9.2 & 4.7 \\
\hline Honduras & 484 & 2,614 & 2,821 & 2,477 & 2,618 & 2,811 & 2,920 & 3,136 & 3,329 & 27.2 & 3.7 \\
\hline Guatemala & 596 & 4,236 & 4,460 & 4,019 & 4,232 & 4,524 & 5,031 & 5,379 & 5,845 & 32.3 & 4.9 \\
\hline Nicaragua & 320 & 740 & 820 & 770 & 825 & 914 & 1,016 & 1,081 & 1,140 & 12.7 & 6.5 \\
\hline Panama & 16 & 180 & 245 & 337 & 410 & 368 & 411 & 452 & 760 & 40.8 & 25.0 \\
\hline EI Salvador & 1,765 & 3,709 & 3,755 & 3,402 & 3,472 & 3,644 & 3,910 & 3,971 & 4,236 & 11.2 & 2.1 \\
\hline
\end{tabular}

Source: Pew Research Center.

\section{WHAT IS THE LIKELY TRAJECTORY OF POTENTIAL GROWTH IN THE MEDIUM TERM?}

Scenario analysis implies that potential growth in Central American economies is likely to remain below pre-crisis rates. Prospects for the components of potential growth-labor, capital, and TFP_are considered over the period from 2015 to 2020 . The scenario analysis builds on the analysis of potential growth until 2014 and extends it, based on projected demographic patterns and the experience from past financial crises which can have longlasting effect on investment-to-capital ratios. Potential growth is likely to remain on average at 4 percent during 2015-20. These scenarios are subject to significant uncertainty, as a number of country-specific factors could influence potential growth, and the evolution of TFP growth in the medium term. Finally, these scenarios do not assume policy changes that could boost potential growth in the medium term.

Potential employment growth is expected to decline further in the medium term, with the highest declines in Costa Rica, Honduras, and Nicaragua.

- $\quad$ This reflects demographic factors which are a drag on both the working-age population and trend labor force participation rates. Population growth is likely to 
slow faster in almost all Central American economies and, if the large migration rates are accounted for, this trend could be exacerbated in countries such as El Salvador, Nicaragua, Guatemala, and Honduras. Aging is expected to accelerate (but levels are still low in Guatemala, Honduras, and Nicaragua compared to the rest of Central America), lowering trend labor force participation rates, and together with slower population growth, reducing potential employment growth in the medium term (Figure 9).

- In Costa Rica, declines in the growth of the working age-population (from an average of 2.1 for the 2008-14 period to an average of 1.6 percent for the 2015-20 period) and labor force participation are expected to result in a large decline in potential employment growth - the highest in the region (from 2.6 to 1.9 percent). Potential employment growth is expected to fall by $0.3-0.4$ percentage points in Honduras, Nicaragua, and the Dominican Republic, due to both declines in working-age population growth and labor force participation growth. In Panama, potential employment growth is expected to fall by 0.2 percentage points due to declining growth in working-age population and labor force participation. In El Salvador, the working-age population growth is expected to decline, while labor force participation growth to increase, resulting in slightly lower potential employment growth. Guatemala's potential employment growth is not expected to change much in the medium term (Figure 9).

Capital growth is expected to slow further from current rates. Investment-to-capital ratios have rebounded somewhat in Costa Rica and Nicaragua since 2011, have fallen slightly in the Dominican Republic and Honduras, and have not changed much in El Salvador, Guatemala and Panama. However, overall, investment-to-capital ratios are likely to remain below pre-crisis rates. This is because of less favorable external financing conditions, infrastructure bottlenecks, and weaknesses in the institutional, regulatory, and legal environment. If investment-to-capital ratios remain at rates observed in 2014, capital growth will remain 2 to 2.5 percentage points below pre-crisis rates in all economies (and over 3.5 percentage points in Honduras), except in Costa Rica, Panama and Nicaragua where the investment-to-capital ratio have not been affected by the crisis (Figure 8). In Nicaragua, capital growth rebounded in the period 2011-14 to higher than pre-crisis rates, which, if sustained, could support a higher potential growth in the coming years.

TFP growth is expected to remain below pre-crisis rates over the next six years, consistent with more sluggish potential growth in advanced economies (as reported in Chapter 3 of the April 2015 WEO). TFP is projected to grow at the 2002-14 average growth rates, given that pre-crisis rates were relatively high compared to historical rates. Assumptions for Guatemala and Nicaragua are different: for Guatemala, it is assumed that TFP will grow at the 2011-14 average growth rates, given consistently smaller negative TFP growth rates turning into small positive TFP growth rates in the past few years, while for Nicaragua, it is assumed that TFP will grow at half the rate of the 2011-14 average growth rates, given certain improvements in TFP in this period compared to the negative TFP in the 2000s (Figure 10). TFP performance, which remains a concern in many Central American economies despite its recent improvement (i.e., in the Dominican Republic and Nicaragua), 
will be pivotal to sustain growth rates in the region in the future. In case TFP performance proves to be weaker than envisaged (i.e., below the 2002-14 average), the impact on potential growth rate could be substantial. In Nicaragua, the recent increase in TFP growth to above 1 percent could be sustained, given its continued upward trend since 2011, and contribute to higher potential growth in the coming years; in fact, Nicaragua experienced a boost in potential growth in 2011-14 that surpasses pre-crisis rates.

\section{Conclusion and Policy Recommendations}

Given a possible moderation of capital accumulation and the existence of natural constraints on labor, potential growth will remain moderate in the region unless TFP performance improves significantly in the future. Growth of physical capital is likely to remain below pre-crisis rates, because of less favorable external financing conditions with respect to 2007, and weaknesses in the institutional, regulatory, and legal and judicial environment.

The contribution of labor to output growth will likely decline due to some natural constraints. These include: (i) slower population growth; (ii) population ageing; (iii) limited room to further increase labor force participation rates, given that they are already high compared to other emerging economies; and (iv) limited space for further increases in employment rates - unemployment rates have declined significantly and are now at the NAIRU in most countries (except in Costa Rica where they are higher than the steady-state (long-run) rates and in the Dominican Republic where they remain at 14 percent).

However, if the demographic dividends mentioned above are managed wisely, increases in labor and capital could boost potential growth. Whether the first dividend is realized depends on the level of education of the young, timing and level of childbearing, and incentives for young parents to work, while policies that focus resources on health care and those related to tax incentives and pensions could support productivity at older ages. The second dividend could be realized if workers are encouraged to save for retirement and invest their savings domestically which will raise capital relative to output.

Relative to emerging economies, most Central American economies perform poorly in various facets of innovation. This includes spending on $R \& D$, tertiary enrollment rates, number of patent applications, FDI inflows, ease of protecting investors, knowledgeintensive employment, and creative services exports (Appendix II Figure 1). Enhancing $\mathrm{R} \& \mathrm{D} /$ technological diffusion will require strengthening institutions, human capital and research, and achieving higher business and market sophistication, and competition in product and labor markets. Important improvements in the quality of schooling are needed to enhance human capital.

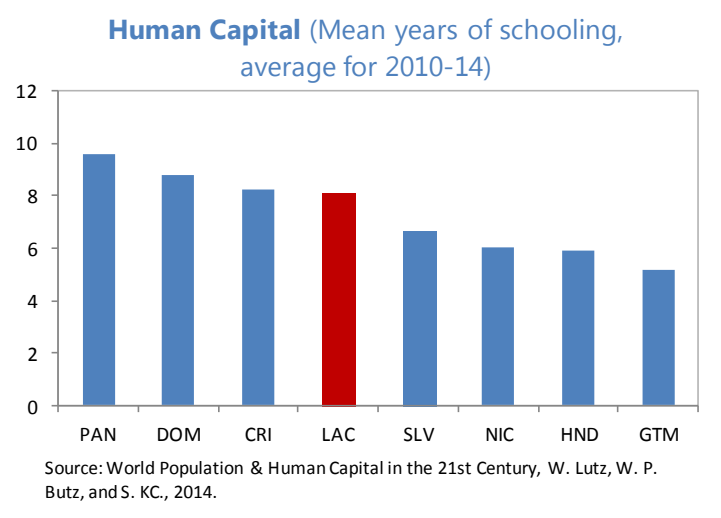


Policies should also prioritize mobilizing domestic savings to invest and build a higher capital stock. Investment-to-capital ratios are lowest in Guatemala, Nicaragua, and El Salvador, and even in Costa Rica, the Dominican Republic, and Honduras, they are lower compared to emerging markets. Attracting private domestic and foreign investment will require reducing policy uncertainties, strengthening institutions to secure property rights and reduce red tape and corruption, ensuring legal and judicial stability, and improving security (Appendix II Figure 4 on crime). Higher and more efficient public investment is critical to address infrastructure deficiencies.

\section{World Economic Forum-based surveys suggest certain labor market rigidities in several Central American economies (i.e., Dominican Republic, Honduras, Nicaragua, El Salvador). These include inefficiencies in wage determination, alignment of pay with productivity, capacity to retain talent, mismatches between skills and jobs, and high informality in almost all of them. Removing these rigidities will improve labor productivity. Facilitating access to social security systems, reducing tax distortions, simplifying tax filing and business licensing procedures are reforms that would help reduce informality.}




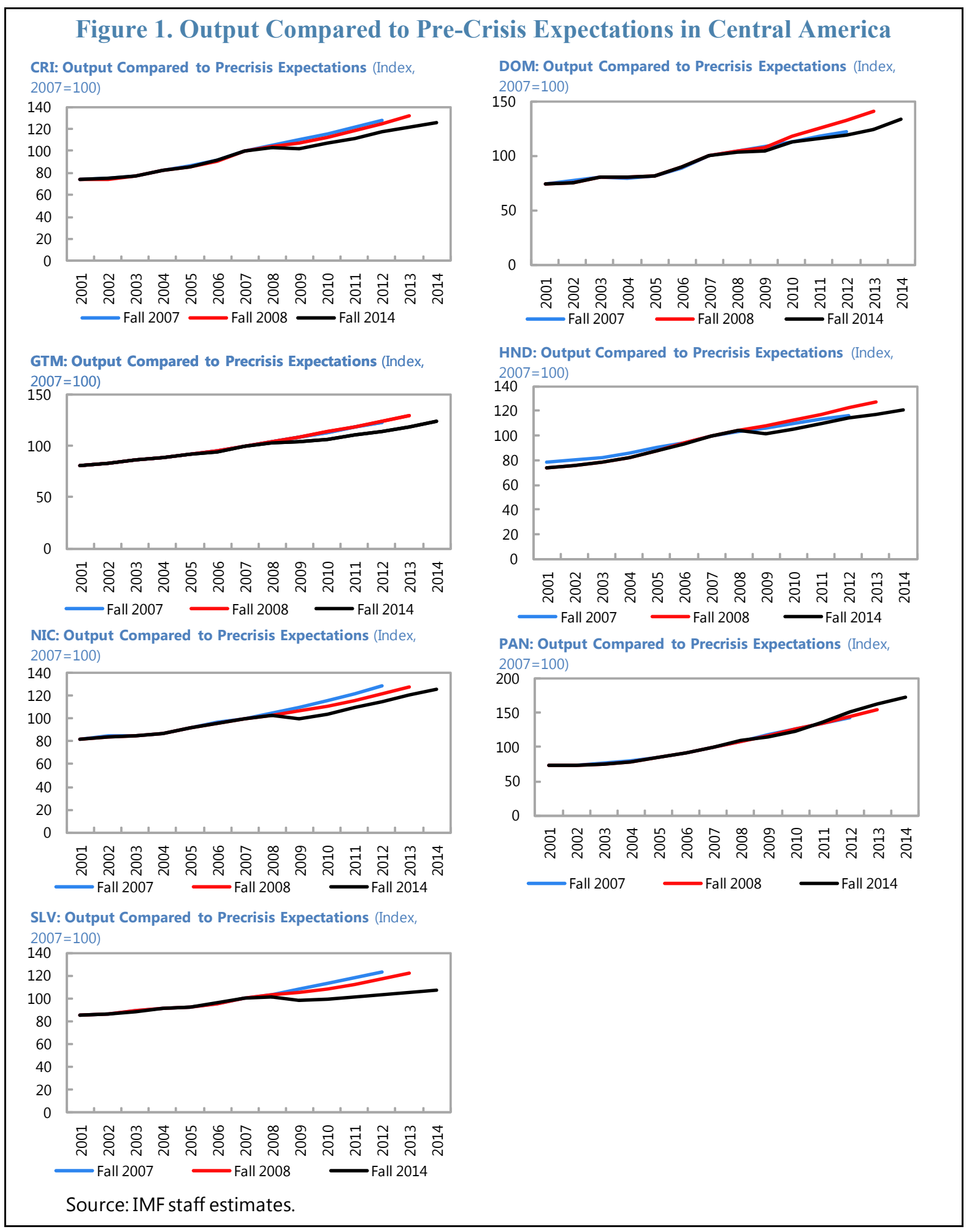

CInternational Monetary Fund. Not for Redistribution 


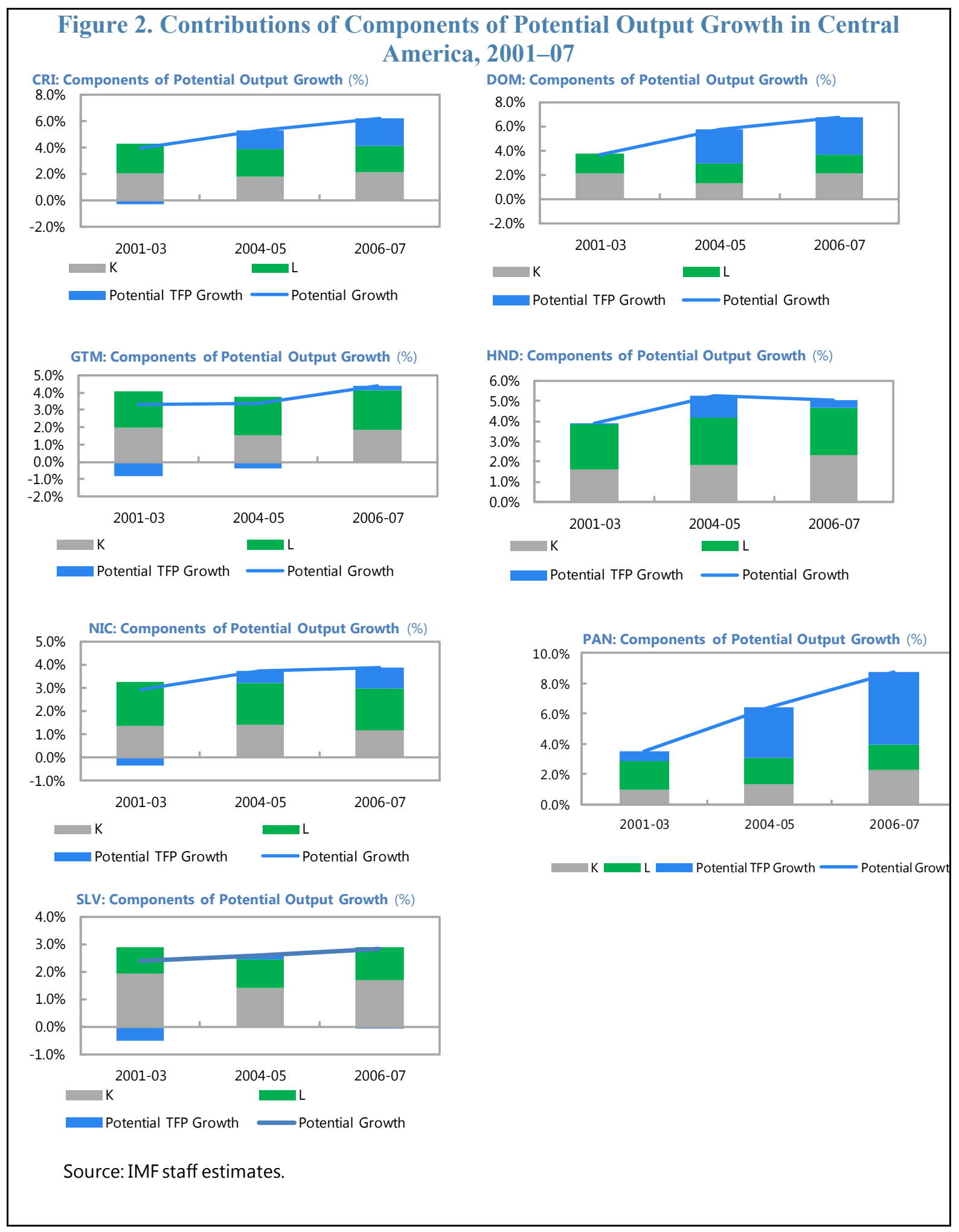

CInternational Monetary Fund. Not for Redistribution 


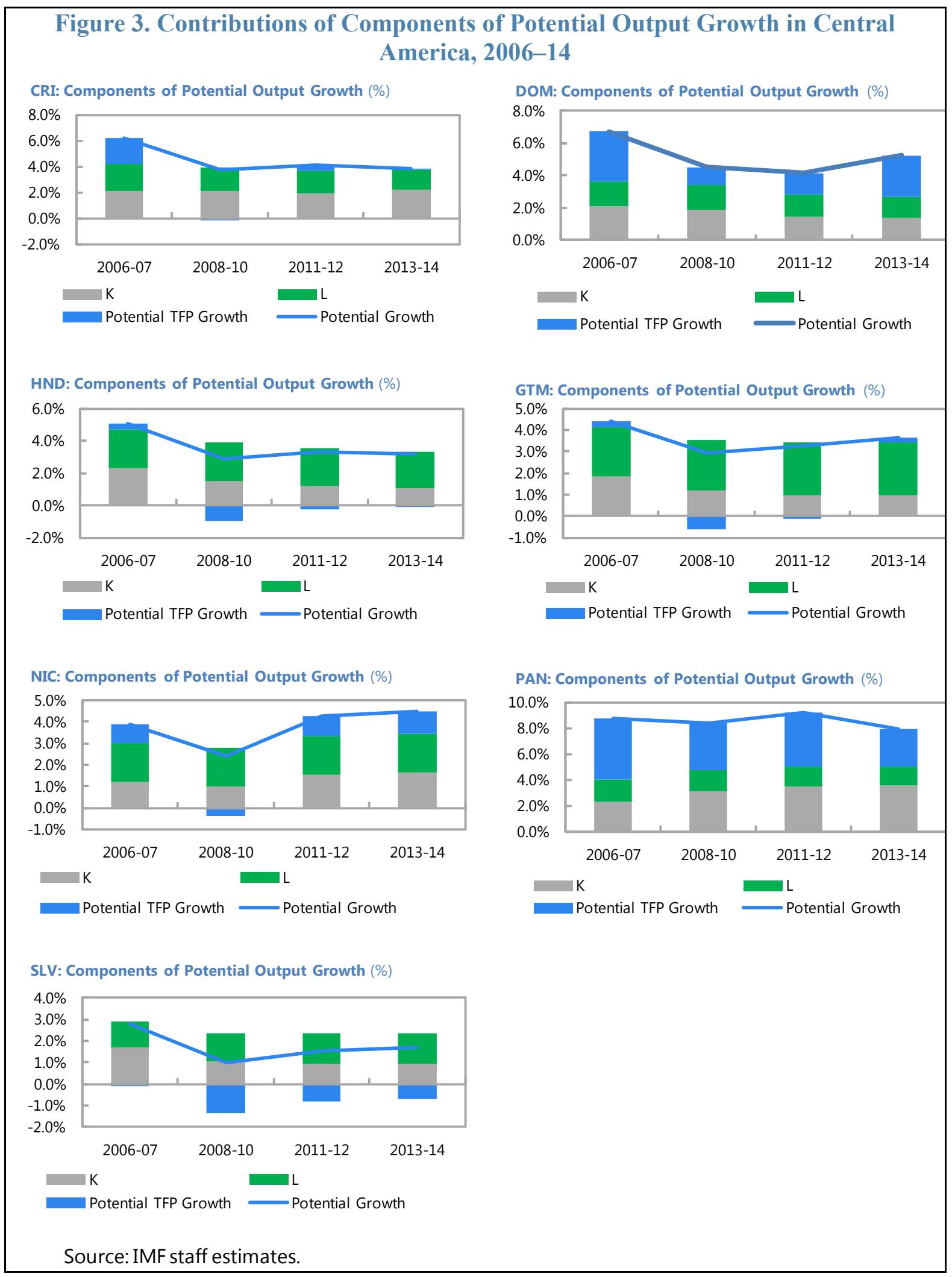

CInternational Monetary Fund. Not for Redistribution 


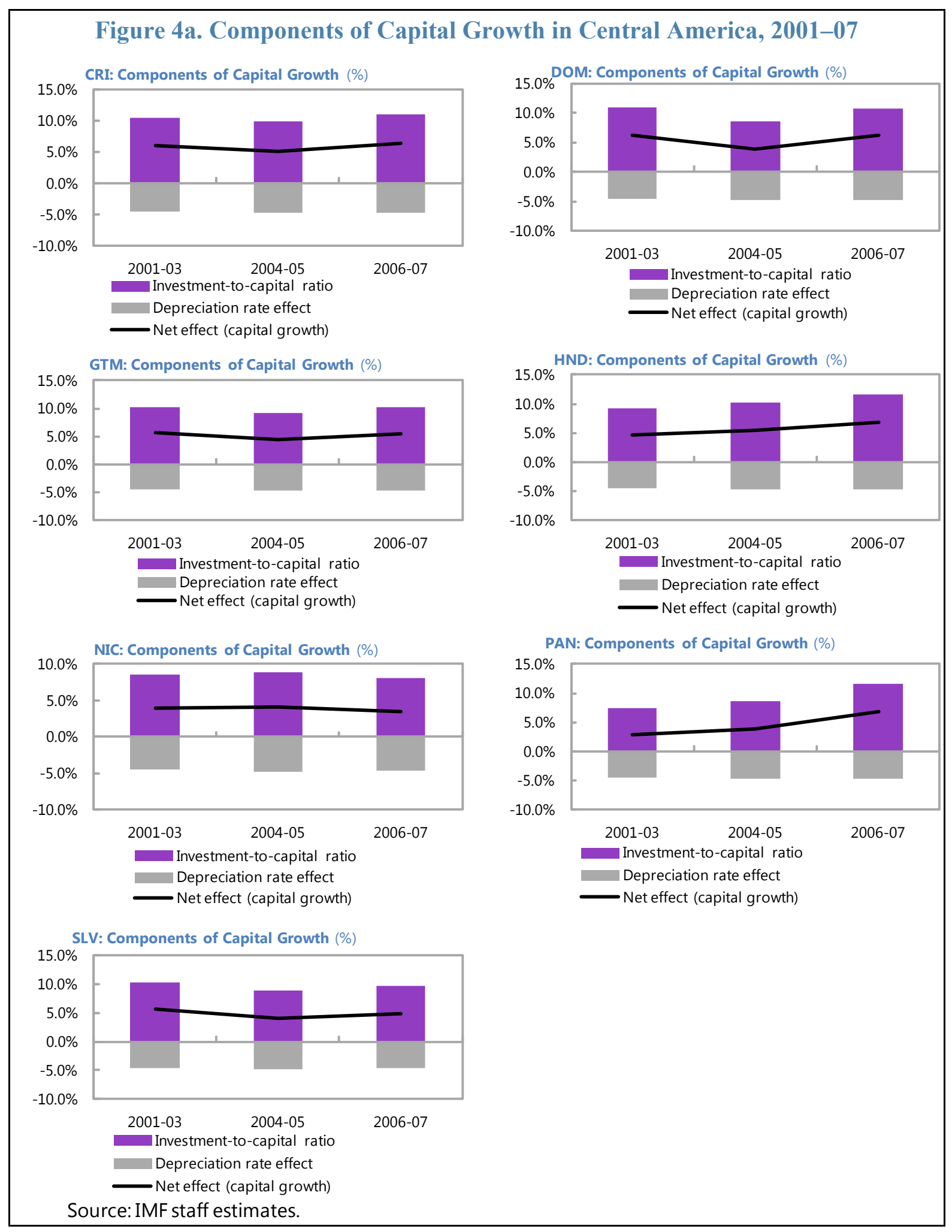

CInternational Monetary Fund. Not for Redistribution 
Figure 4b. Capital Goods Imports-to-Total Imports in Central America, 2000-14
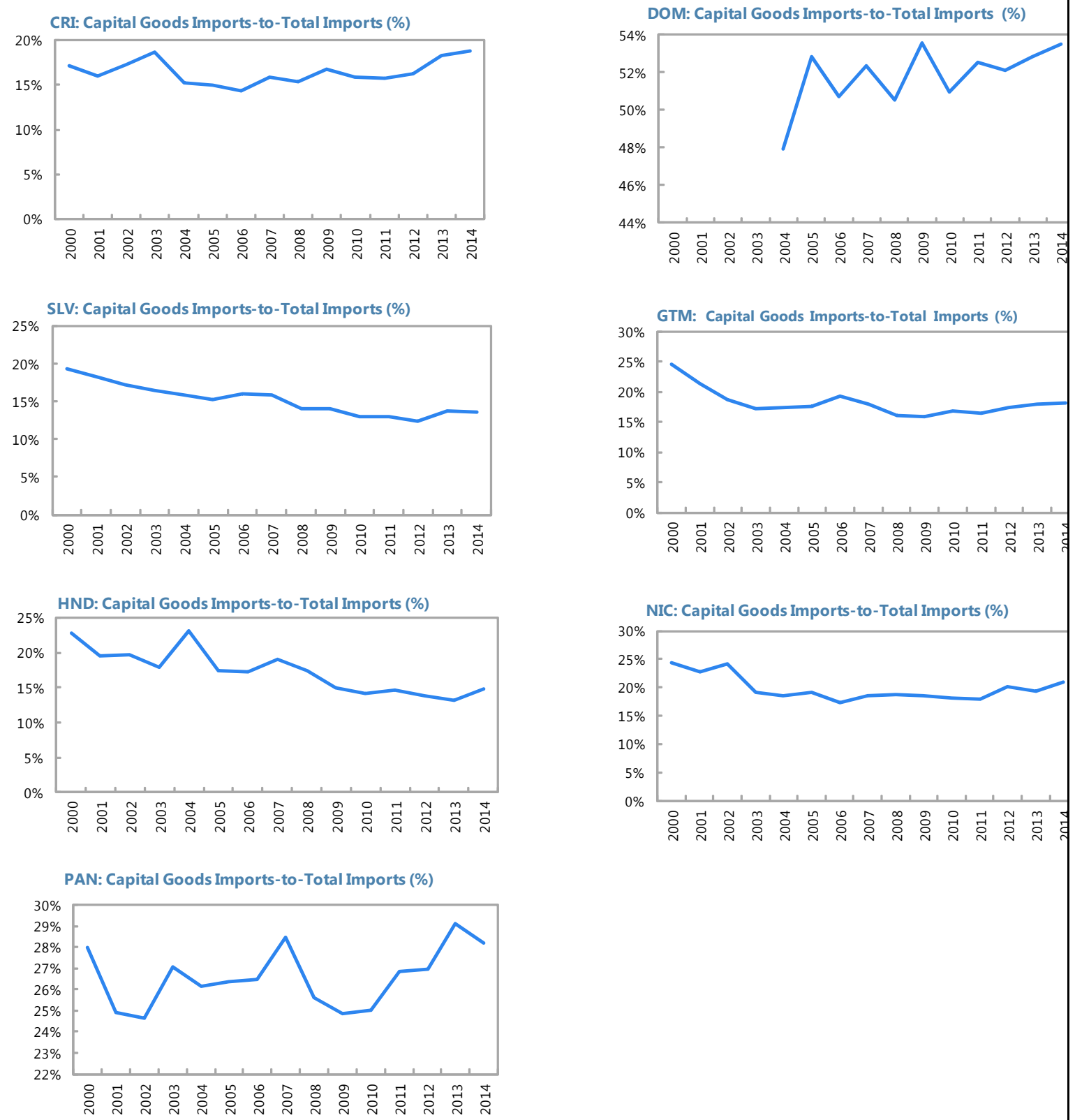

Source: IMF staff estimates. 
Figure 5. Components of Capital Growth in Central America, 2006-14
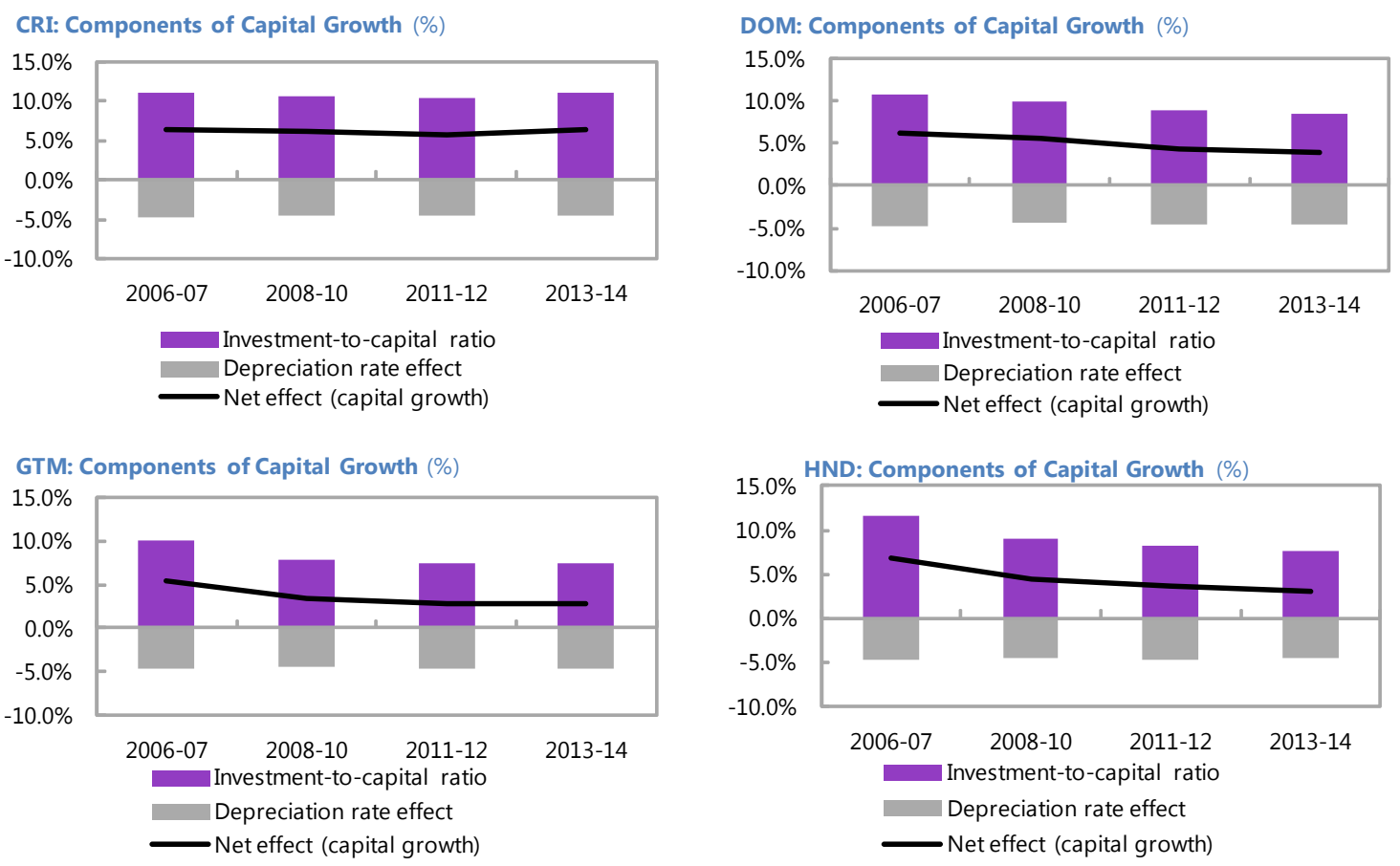

NIC: Components of Capital Growth (\%)
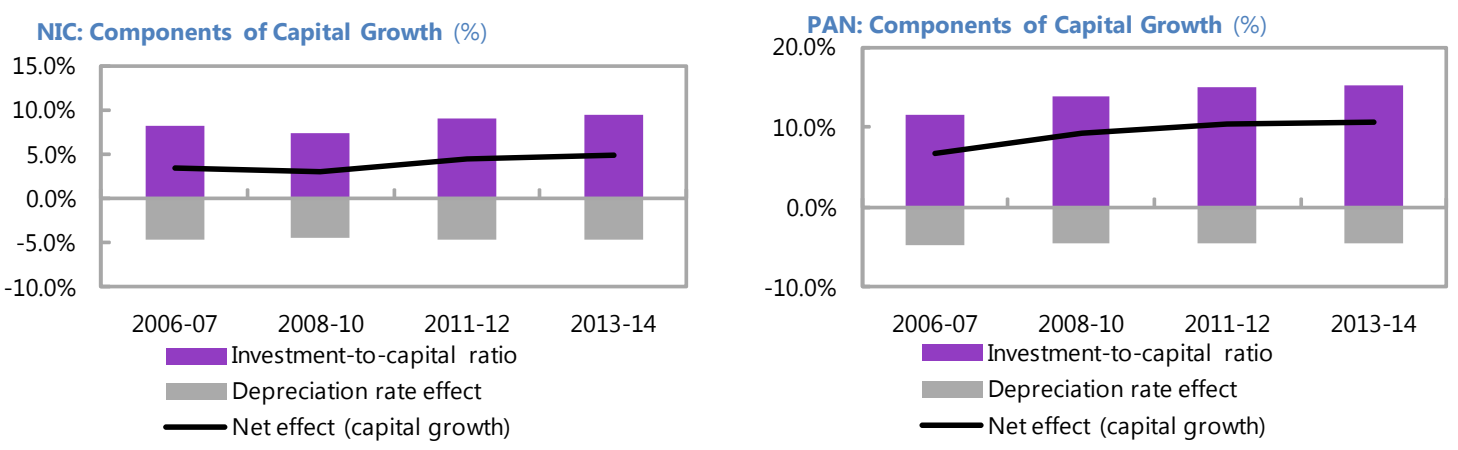

SLV: Components of Capital Growth (\%)

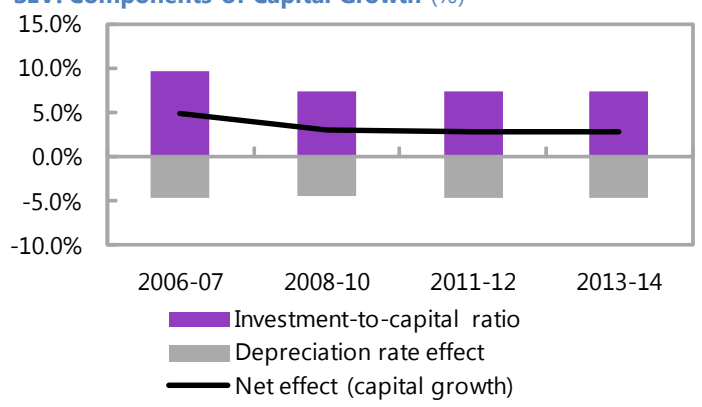

Source: IMF staff estimates. 

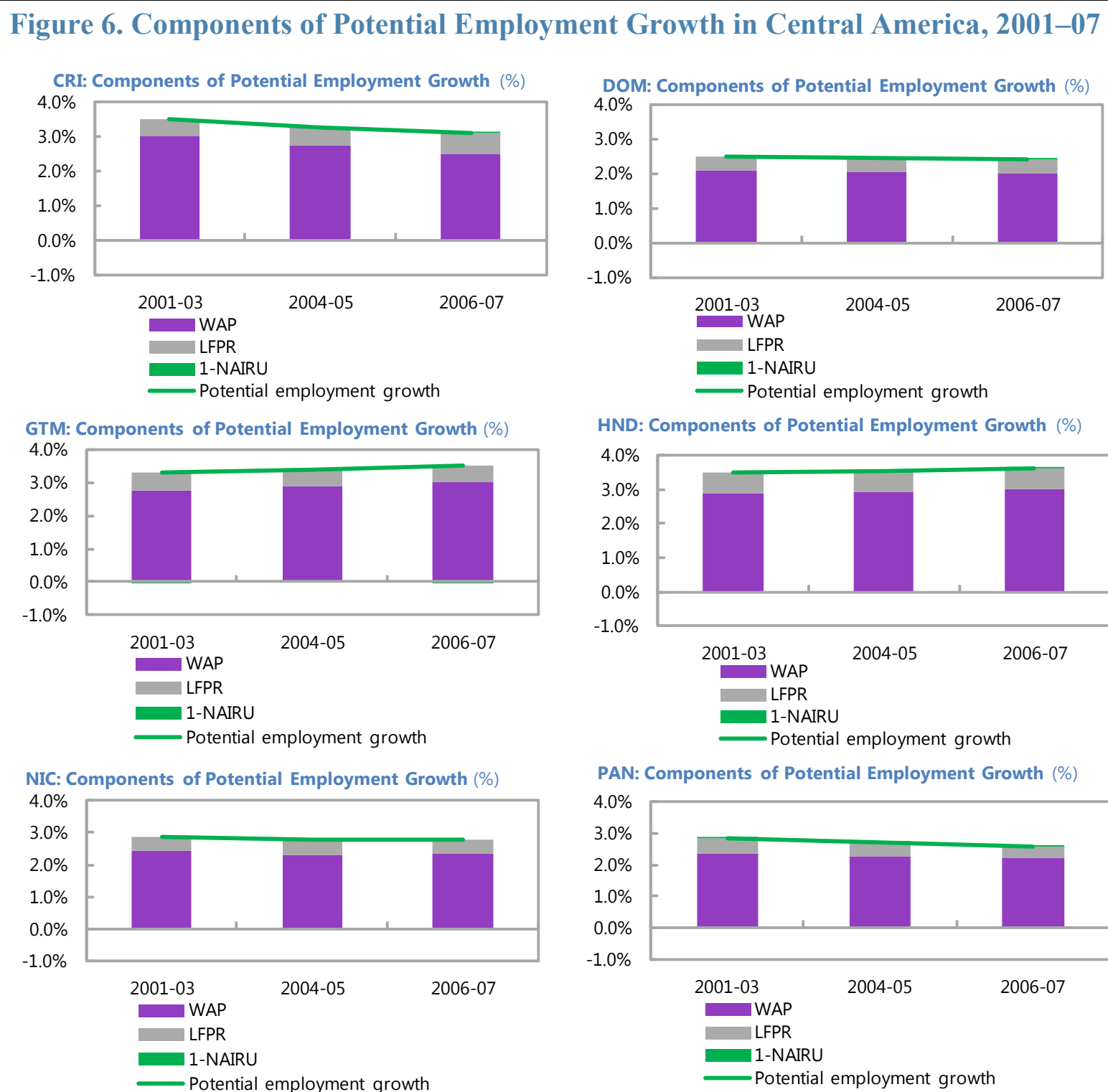

HND: Components of Potential Employment Growth (\%)

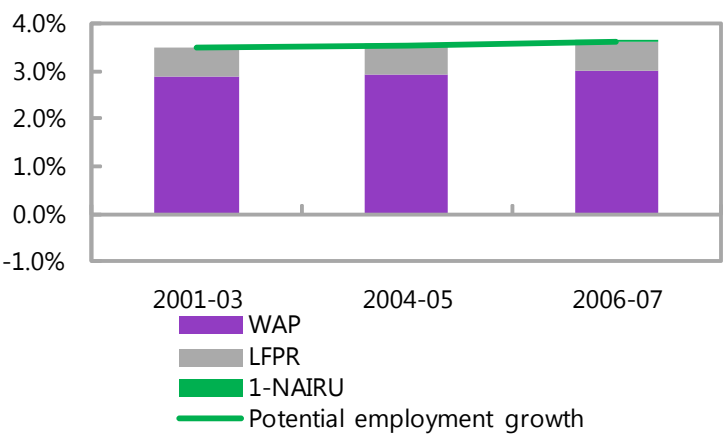

PAN: Components of Potential Employment Growth (\%)

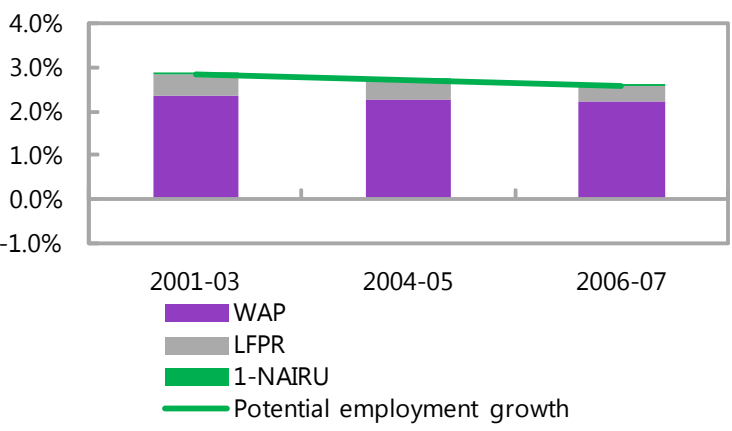

SLV: Components of Potential Employment Growth (\%)

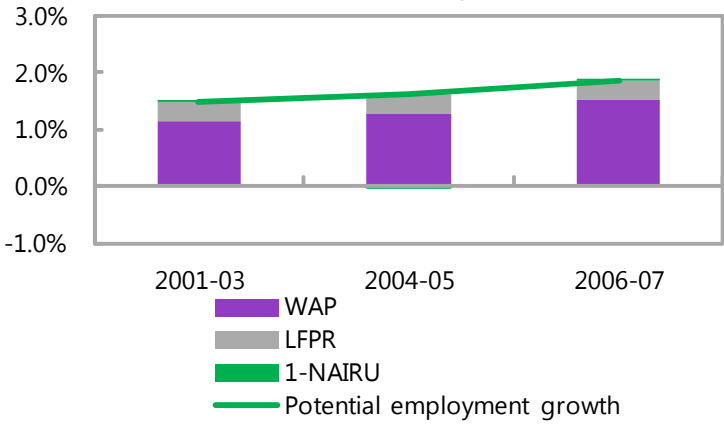

Source: IMF staff estimates. 


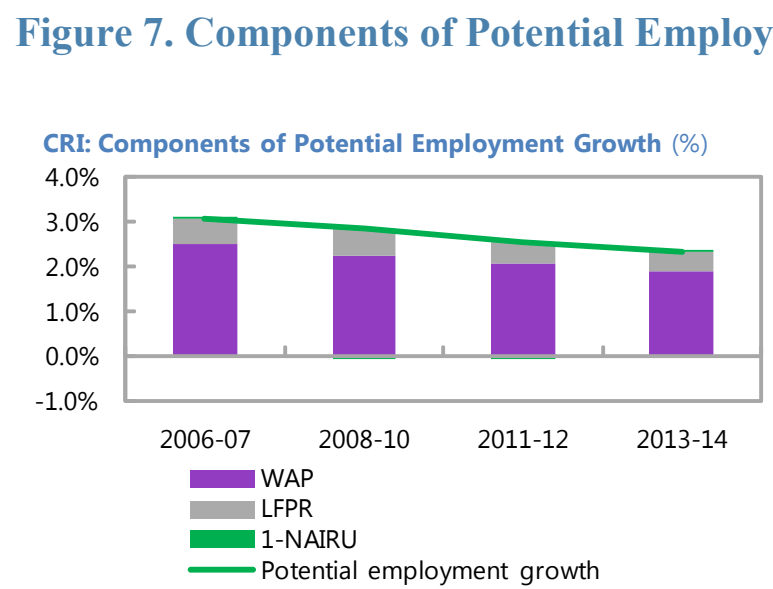

GTM: Components of Potential Employment Growth (\%)

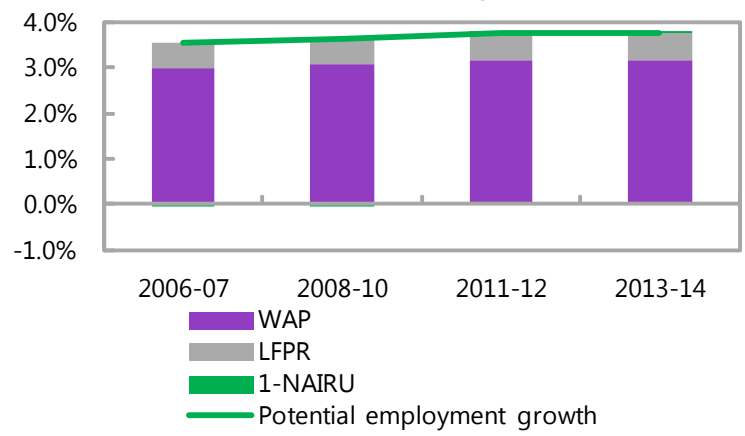

NIC: Components of Potential Employment Growth (\%)

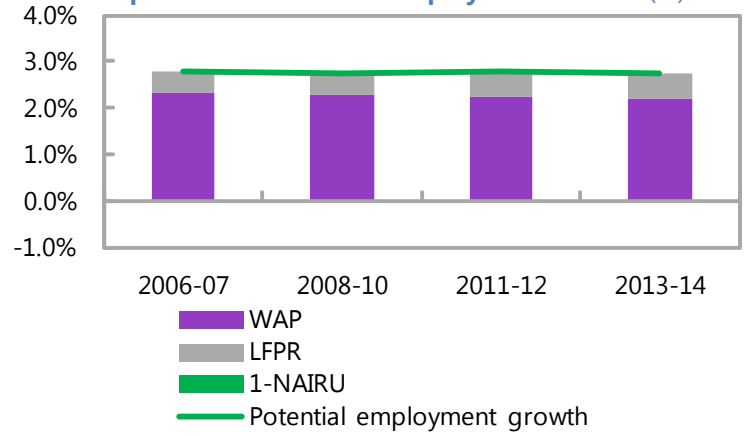

SLV: Components of Potential Employment Growth (\%)

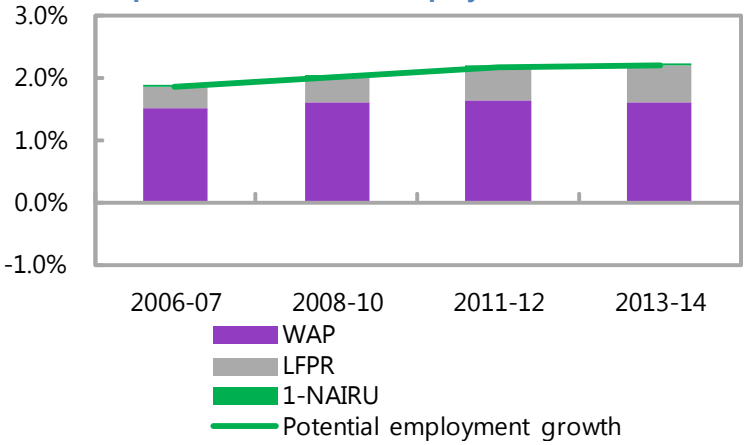

Source: IMF staff estimates.

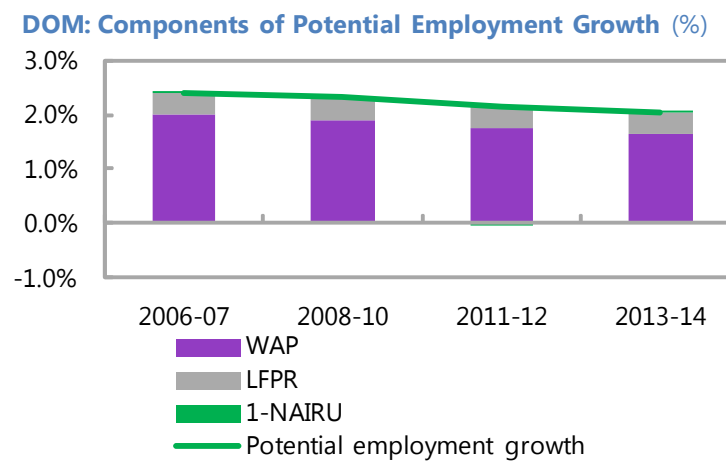

HND: Components of Potential Employment Growth (\%)

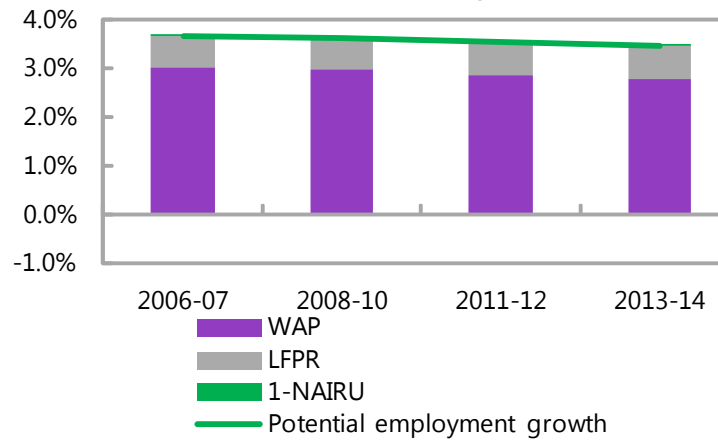

PAN: Components of Potential Employment Growth (\%) $3.0 \%$

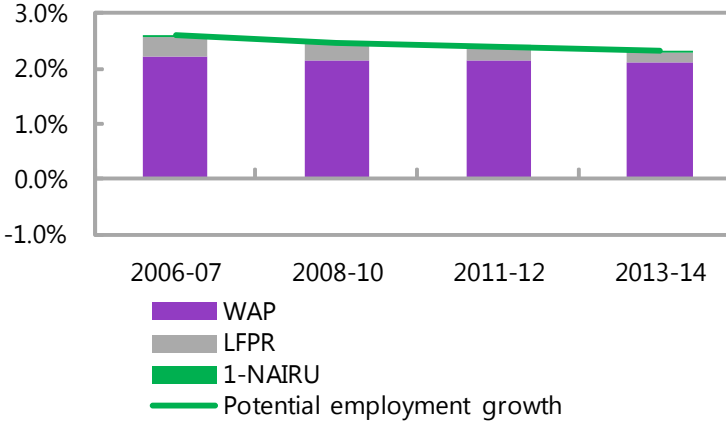


Figure 8. Investment-to-Capital Ratio in Central America, 2001-19
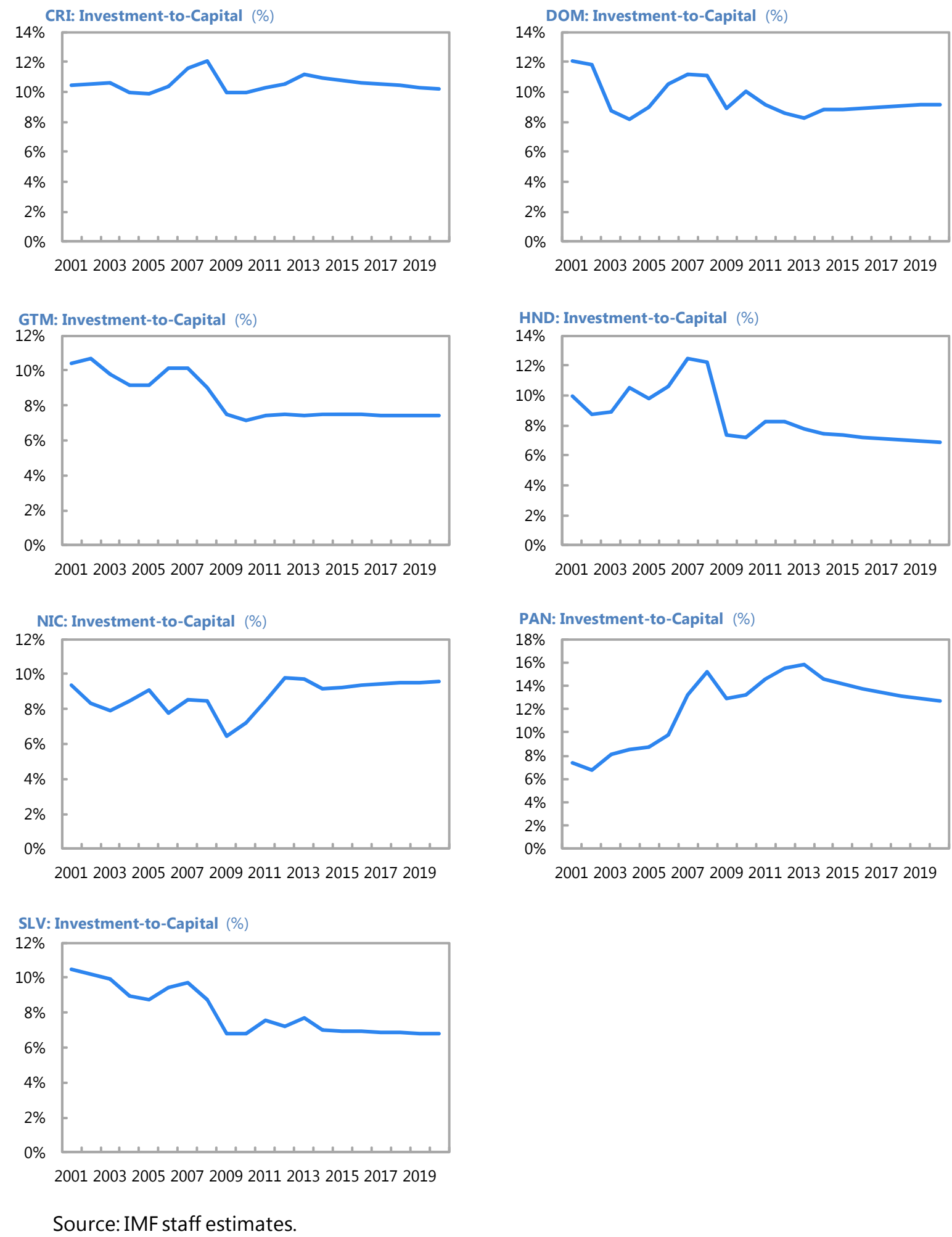


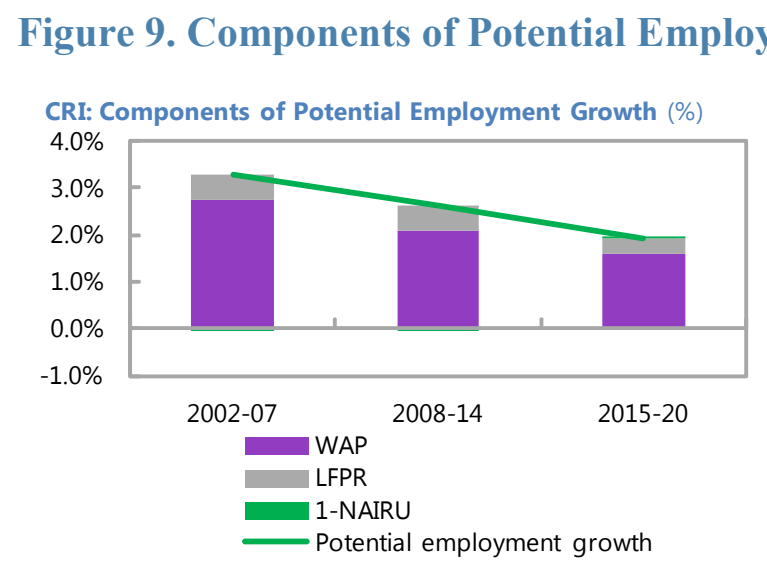

GTM: Components of Potential Employment Growth (\%)

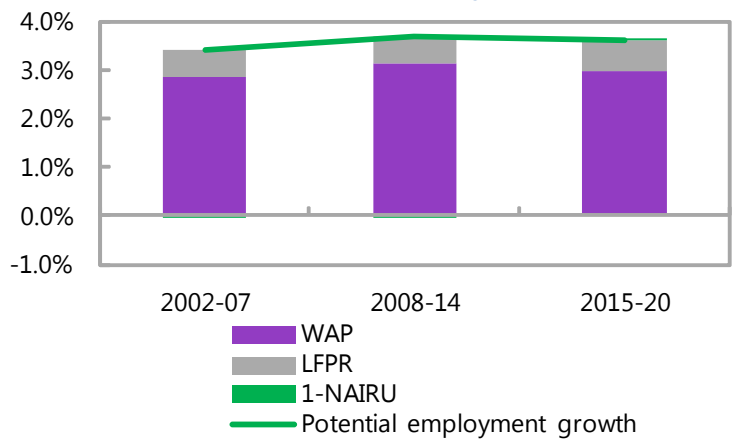

NIC: Components of Potential Employment Growth (\%)
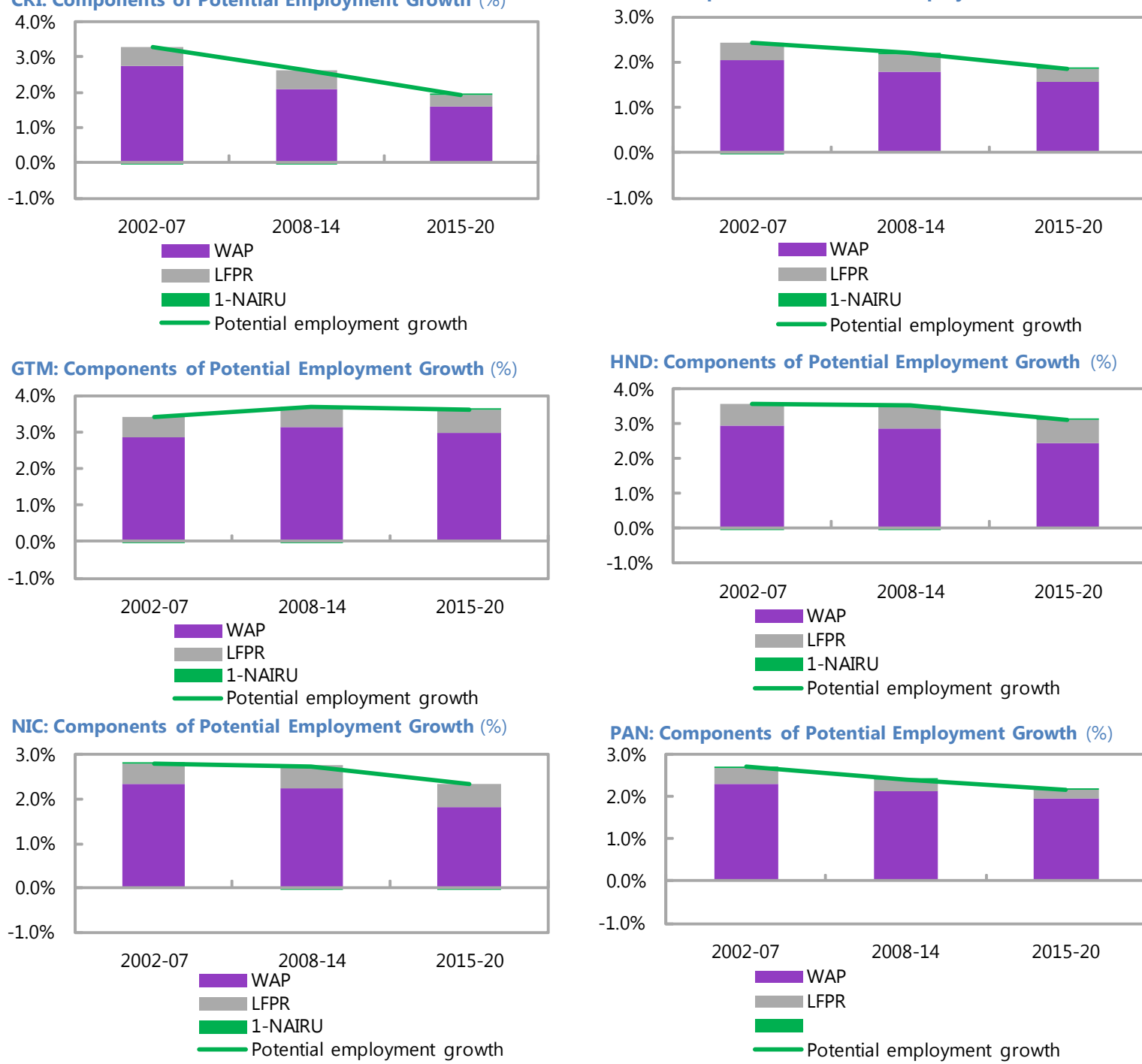

HND: Components of Potential Employment Growth (\%)

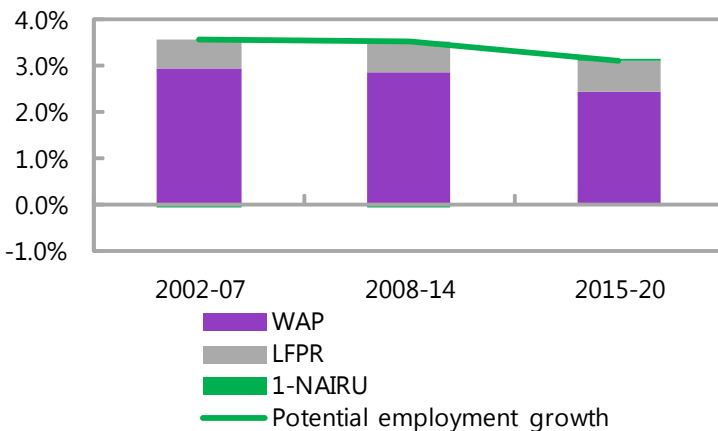

PAN: Components of Potential Employment Growth (\%)

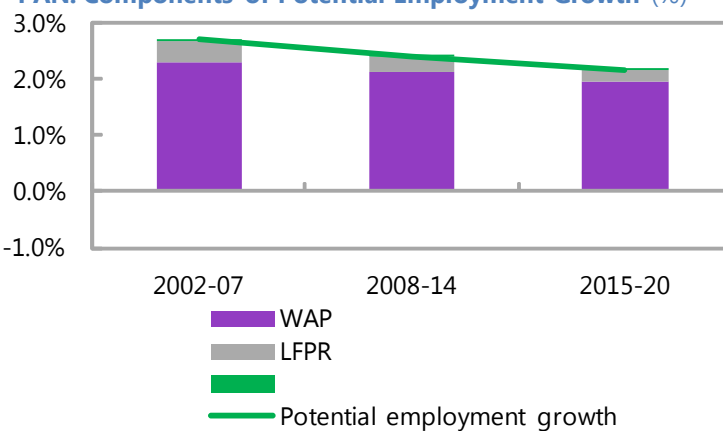

SLV: Components of Potential Employment Growth (\%)

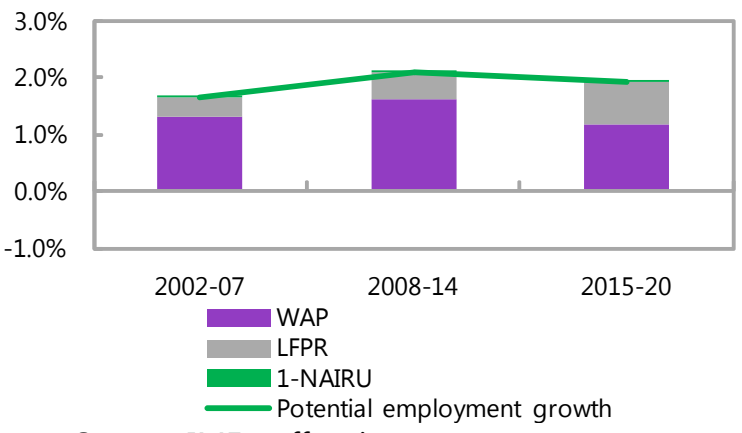

Source: IMF staff estimates. 


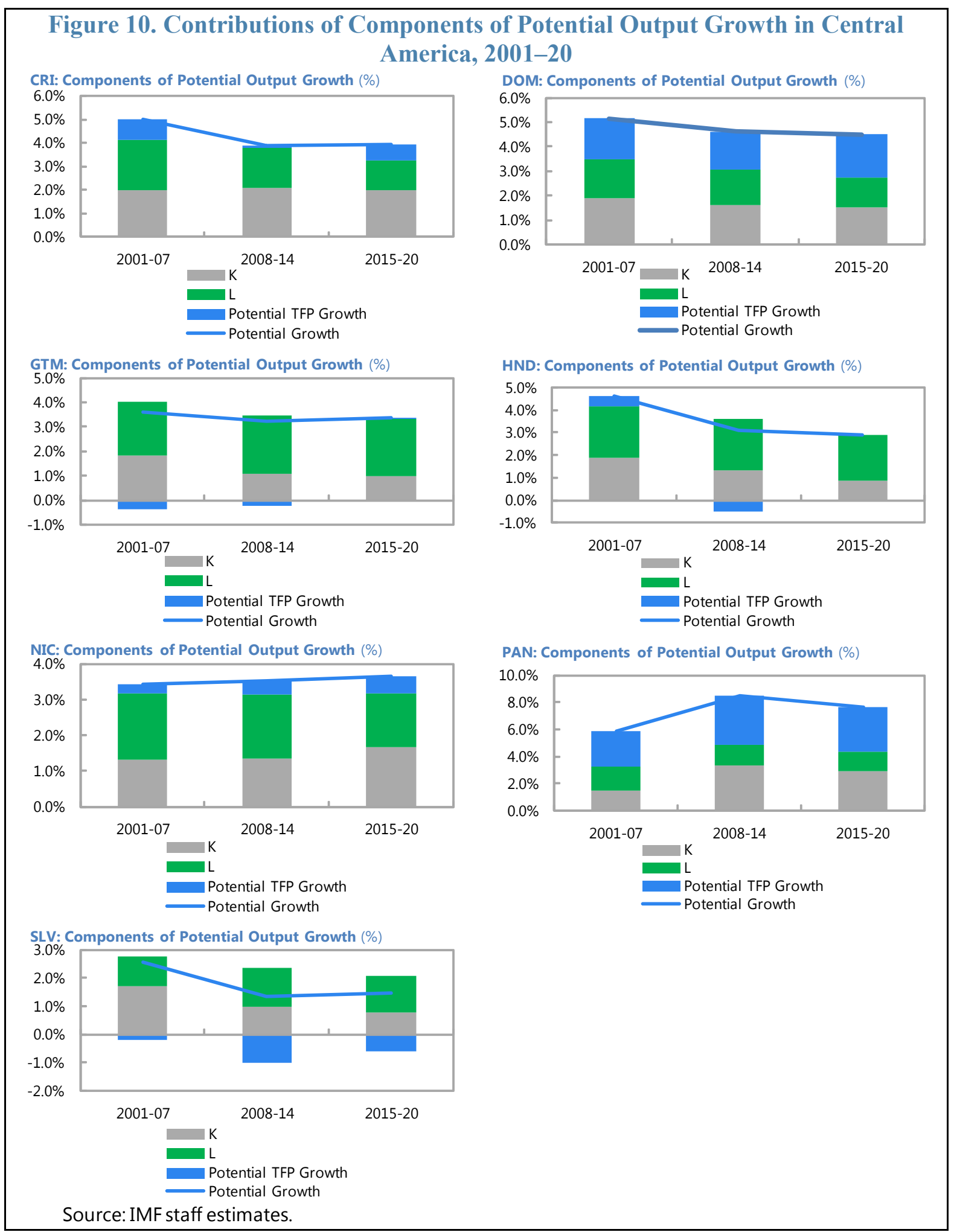

CInternational Monetary Fund. Not for Redistribution 


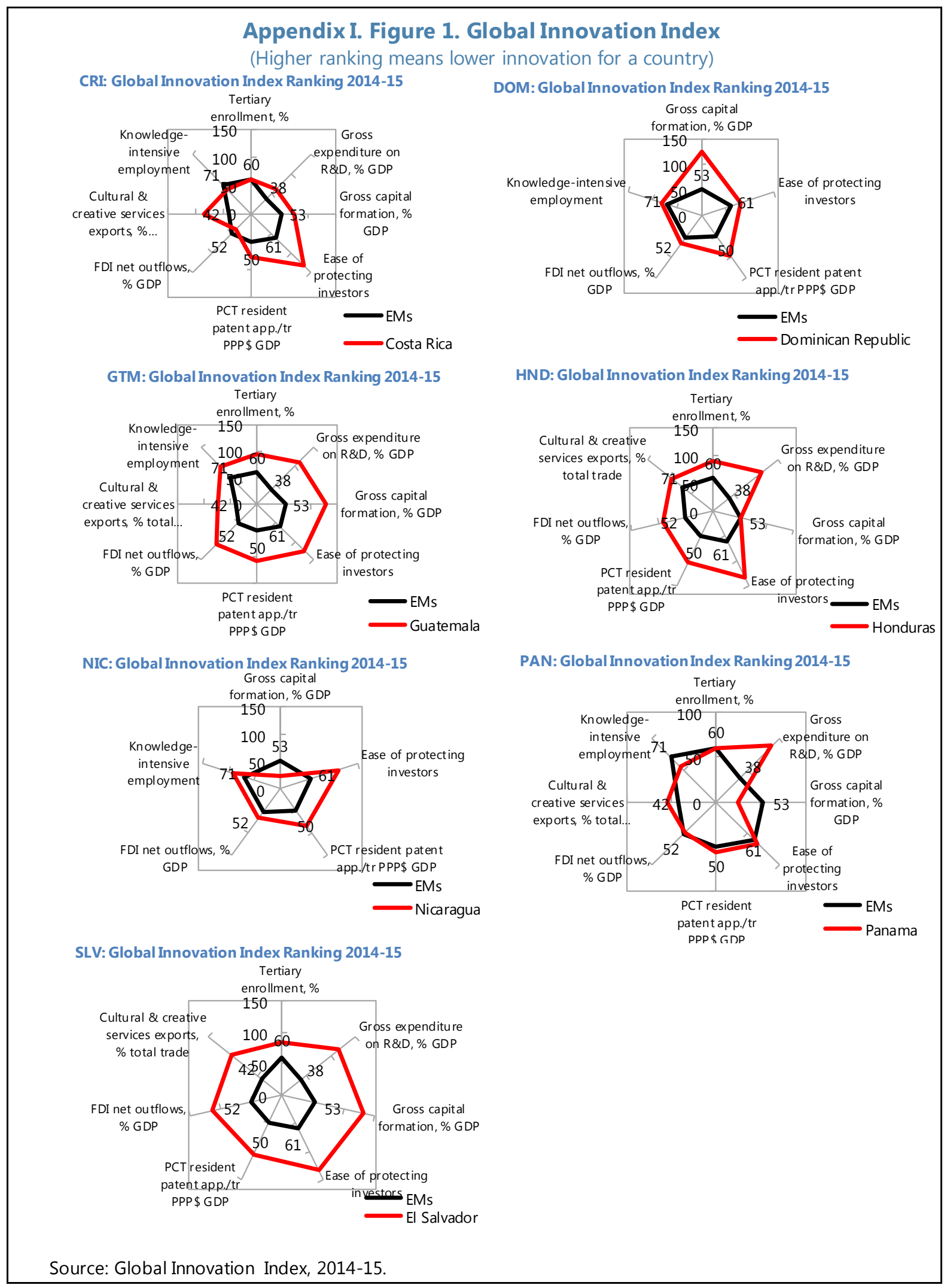

\section{CInternational Monetary Fund. Not for Redistribution}




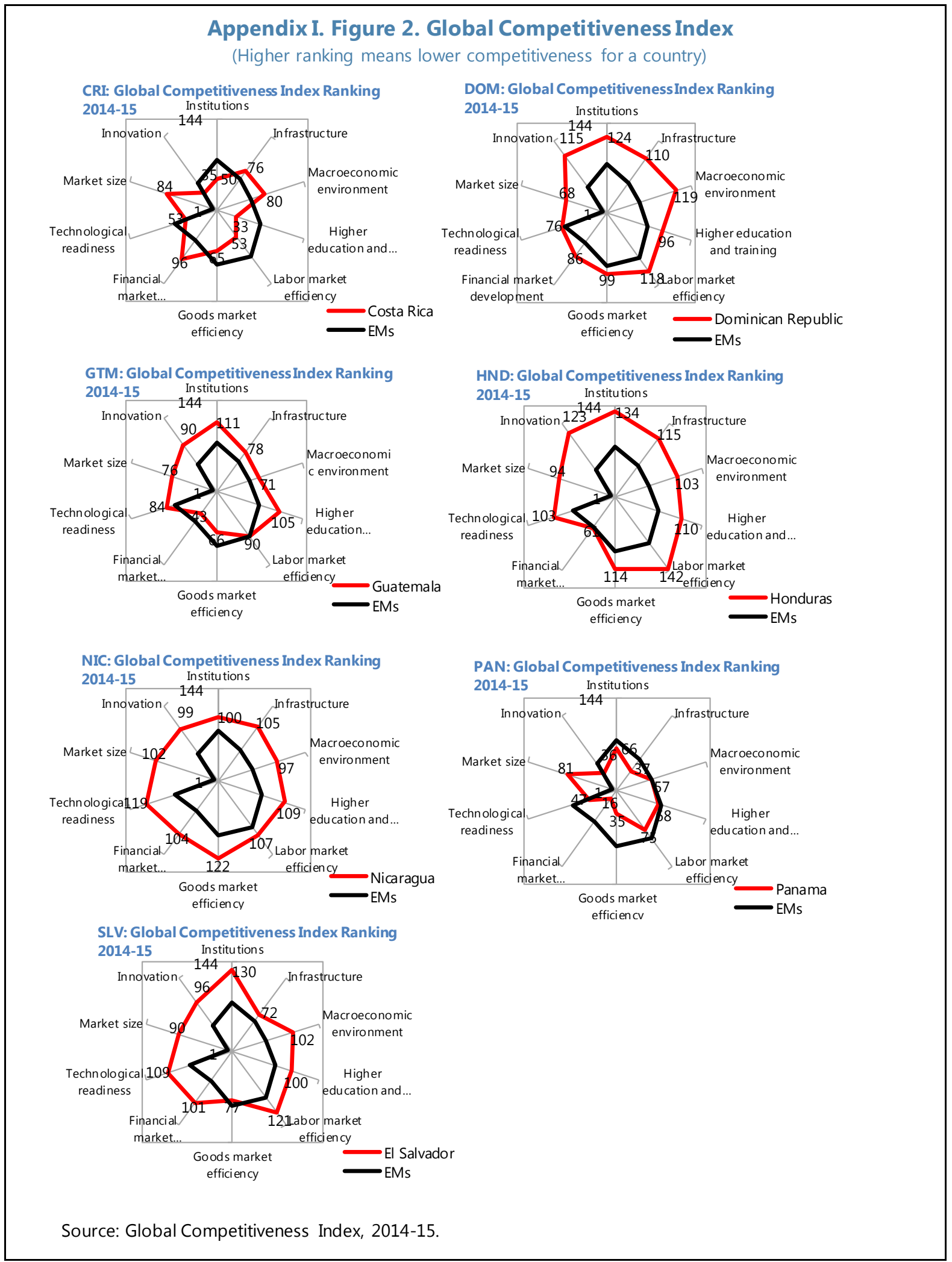

CInternational Monetary Fund. Not for Redistribution 


\section{Appendix I. Figure 3. Doing Business Indicators}

(Higher ranking means lower ease of doing business for a country)

CRI: Doing Business Ranking, 2015

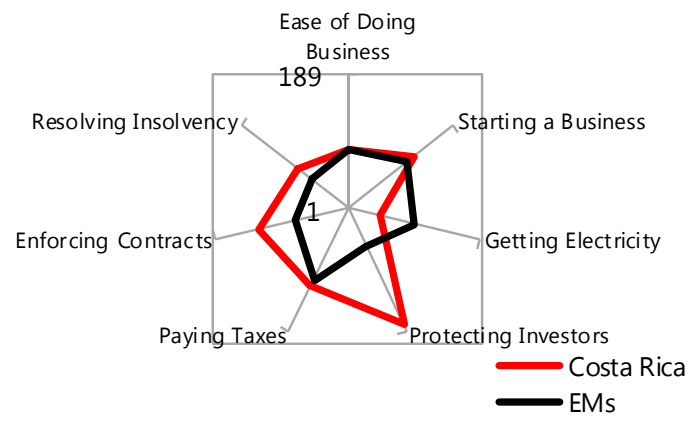

GTM: Doing Business Ranking, 2015

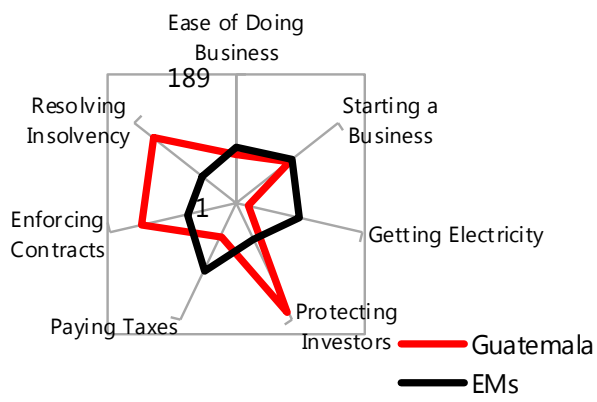

NIC: Doing Business Ranking, 2015

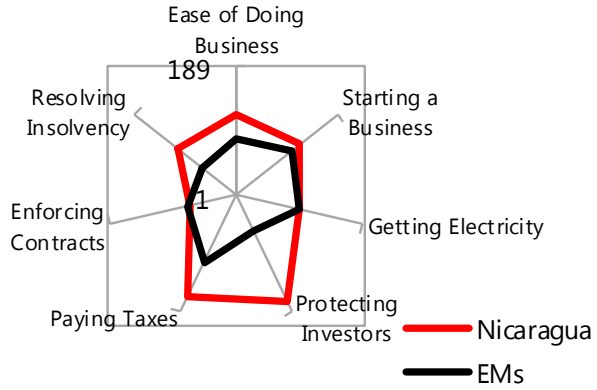

SLV: Doing Business Ranking, 2015

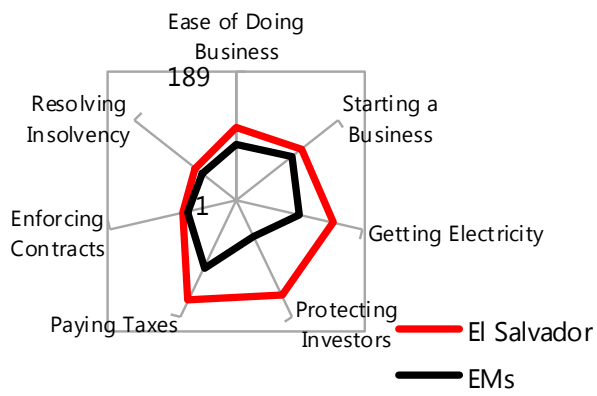

Source: Doing Business Indicators, 2015.
DOM: Doing Business Ranking, 2015

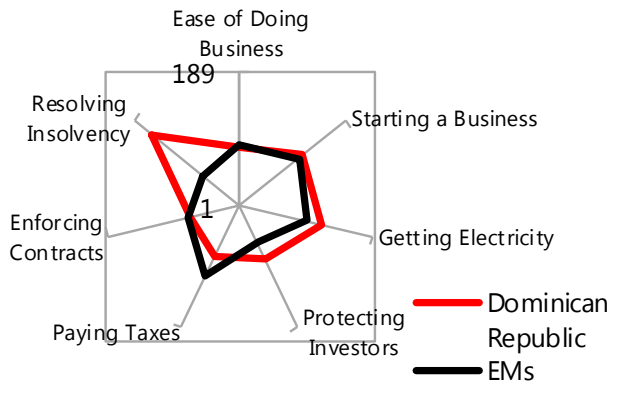

HND: Doing Business Ranking, 2015

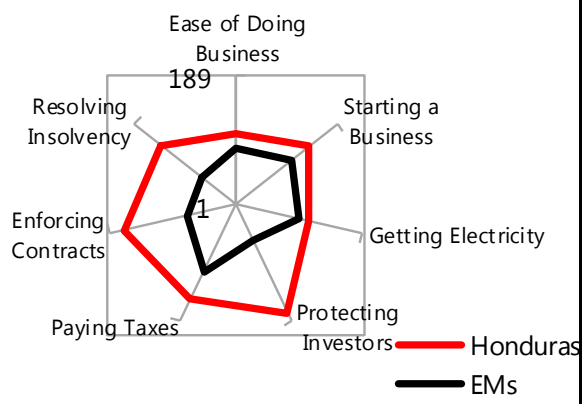

PAN: Doing Business Ranking, 2015

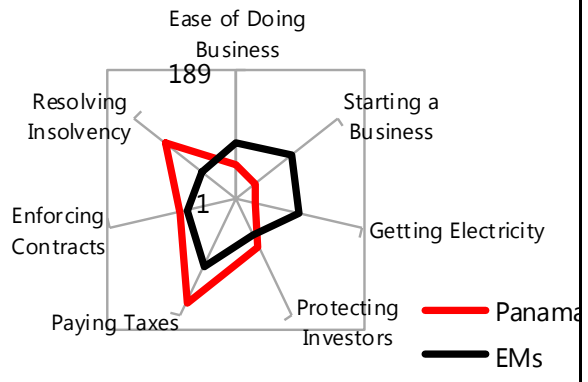




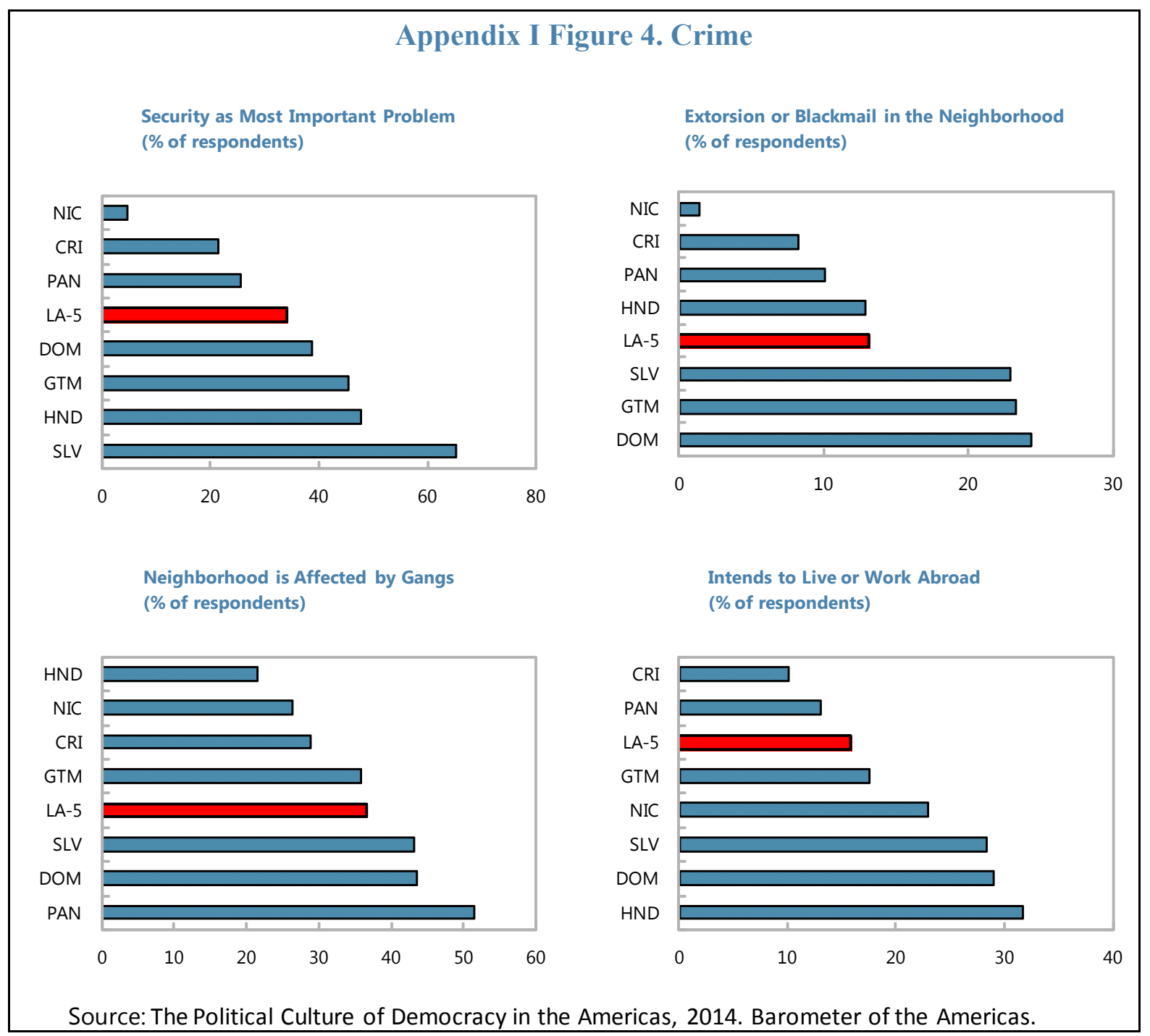

CInternational Monetary Fund. Not for Redistribution 


\section{References}

Aguiar, M., and G. Gopinath, 2007, "Emerging Market Business Cycles: The Cycle Is the Trend," Journal of Political Economy, University of Chicago Press, Vol. 115, pp. 69102.

Benes, J., K. Clinton, R. Garcia-Saltos, M. Johnson, D. Laxton, P. Manchev, and T. Matheson, 2010, "Estimating Potential Output with a Multivariate Filter," IMF Working Paper 10/285 79 (Washington, DC: International Monetary Fund).

—, M. Kumhof, and D. Laxton, 2014, "Financial Crises in DSGE Models: Selected Applications of MAPMOD," Working Paper 14/5679 (Washington, DC: International Monetary Fund).

- M. Kumhof, and D. Laxton, 2014, "Financial Crises in DSGE Models: A Prototype Model.” Working Paper 14/5779 (Washington, DC: International Monetary Fund). and P. N'Diaye, 2004, “A Multivariate Filter for Measuring Potential Output and the NAIRU: Application to The Czech Republic," IMF Working Paper 04/45 (Washington, DC: International Monetary Fund).

Blagrave, P., R. Garcia-Saltos, D. Laxton, and F. Zhang, 2014, "A Simple Multivariate Filter for Estimating Potential Output," IMF Working Paper 15/79 (Washington, DC: International Monetary Fund).

Borio, C., P. Disyatat, and M. Juselius, 2013, "Rethinking Potential Output: Embedding Information about the Financial Cycle," BIS Working paper no. 404.

Cotis, J.P., J. Elmeskov, and A. Mourougane, 2004, "Estimates of Potential Output: Benefits and Pitfalls from a Policy Perspective," Published in Euro Area Business Cycle: Stylized Facts and Measurement Issues, pp. 35-60.

D’Auria, F, C. Denis, K. Havik, K. McMorrow, C. Planas, R. Raciborski, W. Roger, A. Rossi, 2010, "The Production Function Methodology for Calculating Potential Growth Rates and Output Gaps," European Commission Economic Papers No 420, July.

De Masi, P. R., 1997, “IMF Estimates of Potential Output: Theory and Practice," IMF Working Paper 97/177 79 (Washington, DC: International Monetary Fund).

Giorno, C, P. Richardson, D. Roseveare, and P. van den Noord, 1995, "Estimating Potential Output, Output Gaps and Structural Budget Balances," OECD Working Paper no. 152.

Hamilton, J, 1994, Time Series Analysis, Princeton University Press, New Jersey. 
Hodrick, R. J., and E.C. Prescott, 1997, "Post-War U.S. Business Cycles: An Empirical Investigation," Journal of Money, Credit and Banking, Vol. 29(1), pp. 1-16.

International Monetary Fund (IMF), 2013, “The Dog That Didn't Bark: Has Inflation Been Muzzled or Was It Just Sleeping?” World Economic Outlook, April, Washington.

International Monetary Fund (IMF), 2013, "Is the Growth Momentum in Latin America Sustainable?” Western Hemisphere Regional Economic Outlook, May, Washington.

International Monetary Fund (IMF), 2015, "Where Are We Headed? Perspectives on Potential Output." World Economic Outlook, April, Washington.

Kuttner, K. N., 1994, “Estimating Potential Output as a Latent Variable," Journal of Business and Economic Statistics, Vol. 12, pp. 361-68.

Laxton, D., and R. Tetlow, 1992, "A Simple Multivariate Filter for the Measurement of Potential Output," Technical Report No. 59 (Ottawa: Bank of Canada).

Ljung, L., 1999, “System Identification: Theory for the User,” Prentice-Hall: New Jersey.

Mishkin, F.S., 2007, “Inflation Dynamics,” Annual Macro Conference, Federal Reserve Bank of San Francisco, March. Available at http://www.federalreserve.gov/newsevents/speech/Mishkin20070323a.htm

Okun, A.M., 1962, "Potential GNP: Its Measurement and Significance," in Proceedings of the Business and Economic Statistics Section, pp. 98-104 (Washington: American Statistical Association).

Prachowny, M., 1993, “Okun's Law: Theoretical Foundations and Revised Estimates,” The Review of Economics and Statistics, Vol. 75, No. 2, pp. 331-336.

Sosa, S., E. Tsounta, and H. Kim, 2013, "Is the Growth Momentum in Latin America Sustainable?" IMF Working Paper 13/109 (Washington, DC: International Monetary Fund).

Riggi, M., and F. Venditti, 2014, "Surprise! Euro Area Inflation has Fallen,” Banca D'Italia Occasional Paper No. 237.

Vetlov, I., T. Hledik, M. Jonsson, H. Kucsera, and M. Pisani, 2011, "Potential Output in DSGE Models,” ECB Working Paper Series No. 1351. 